\title{
A gradient of Gli activity mediates graded Sonic Hedgehog signaling in the neural tube
}

\author{
Despina Stamataki, Fausto Ulloa, Stavroula V. Tsoni, Anita Mynett, and James Briscoe ${ }^{1}$ \\ Developmental Neurobiology, National Institute for Medical Research, Mill Hill, London, NW7 1AA, United Kingdom
}

\begin{abstract}
During development, many signaling factors behave as morphogens, long-range signals eliciting different cellular responses according to their concentration. In ventral regions of the spinal cord, Sonic Hedgehog (Shh) is such a signal and controls the emergence, in precise spatial order, of distinct neuronal subtypes. The Gli family of transcription factors plays a central role in this process. Here we demonstrate that a gradient of Gli activity is sufficient to mediate, cell-autonomously, the full range of Shh responses in the neural tube. The incremental two- to threefold changes in Shh concentration, which determine alternative neuronal subtypes, are mimicked by similar small changes in the level of Gli activity, indicating that a gradient of Gli activity represents the intracellular correlate of graded Shh signaling. Moreover, our analysis suggests that cells integrate the level of signaling over time, consistent with the idea that signal duration, in addition to signal strength, is an important parameter controlling dorsal-ventral patterning. Together, these data indicate that Shh signaling is transduced, without amplification, into a gradient of Gli activity that orchestrates patterning of the ventral neural tube.
\end{abstract}

[Keywords: Hedgehog signaling; graded morphogen signaling; neural tube development; neuronal subtype identity; vertebrate patterning mechanisms]

Received September 24, 2004; revised version accepted January 5, 2005.

During vertebrate development, signals produced by localized sources organize fields of cells and govern the specification of cell fate. Many of these signals appear to act in a graded fashion, imparting positional information in the form of a concentration gradient. In these cases, the distance of a cell from the signal source determines the concentration of signal to which it is exposed, which in turn controls the fate of the responding cell. Signals with these properties have direct concentration-dependent and distance-related effects and are termed morphogens (Lawrence and Struhl 1996; Wolpert 1996; Gurdon and Bourillot 2001). A central issue in developmental biology therefore is to understand how cells perceive and transduce extracellular concentration gradients of a signal and how this results in differential gene expression and cell fates.

The activity of Sonic Hedgehog (Shh) in the spinal cord represents an example where progress has been made in understanding the molecular mechanisms of morphogen action (Ericson et al. 1997a; Hynes et al. 2000; Jessell 2000; Briscoe and Ericson 2001; Briscoe et al. 2001;

${ }^{1}$ Corresponding author.

E-MAIL: james.briscoe@nimr.mrc.ac.uk; FAX 44-20-8816-2523.

Article and publication are at http://www.genesdev.org/cgi/doi/10.1101/ gad.325905.
Gritli-Linde et al. 2001; Ingham and McMahon 2001; Lewis et al. 2001). Distinct neuronal subtypes emerge in a precise spatial order from progenitor cells arrayed along the dorsal-ventral axis of the spinal cord. In ventral regions, Shh signaling acts as a long-range graded signal that controls this pattern of neurogenesis. Moreover, in vitro assays indicate that incremental two- to threefold changes in Shh concentration generate five distinct neuronal subtypes characteristic of the ventral neural tube (Ericson et al. 1997a). Shh acts by regulating the spatial pattern of expression, in ventral progenitor cells, of transcription factors that include members of the homeodomain protein (HD) and basic helix-loop-helix (bHLH) families (Ericson et al. 1997b; Briscoe et al. 2000; Muhr et al. 2001; Novitch et al. 2001; Pierani et al. 2001; Vallstedt et al. 2001). These transcription factors are subdivided into two groups, termed class I and II proteins, on the basis of their mode of regulation by Shh signaling (Briscoe et al. 2000). Class I proteins are repressed by Shh signaling, whereas neural expression of class II proteins requires exposure to Shh (Ericson et al. 1997b; Qiu et al. 1998; Briscoe et al. 1999, 2000; Pabst et al. 2000; Vallstedt et al. 2001). Cross-repressive interactions between pairs of class I and class II proteins define the spatial extent of individual progenitor domains and establish 
sharp boundaries between adjacent domains (Ericson et al. 1997b; Briscoe et al. 2000). Changing the progenitor homeodomain code alters neuronal subtype in a predictable manner, indicating that the profile of class I and class II protein expression within a progenitor cell determines the subtype identity of neurons generated (Briscoe et al. 2000).

Despite the evidence that class I and class II proteins control neural tube patterning, it remains unclear how graded Shh signaling directs the differential expression of these genes. Three zinc finger-containing transcription factors-Gli1, Gli2, and Gli3, homologs of Drosophila Cubitus interruptus (Ci) - are thought to regulate Shh-dependent gene expression (Lee et al. 1997; Sasaki et al. 1997; Ruiz i Altaba 1998; Ingham and McMahon 2001). Similar to Ci, Gli2 and Gli3 (although not Gli1) appear to be bifunctional transcriptional repressors and activators. Proteolytic processing converts Gli2 and Gli3 to transcriptional repressors and, at least in the case of Gli3, the evidence suggests that $\mathrm{Hh}$ signaling regulates this processing (Wang et al. 2000). In mouse embryos, although the lack of Gli1 does not affect dorsalventral patterning of the spinal cord (Matise et al. 1998; Park et al. 2000), embryos lacking Gli2 have defects in the most ventral domains of the neural tube (Ding et al. 1998; Matise et al. 1998; Park et al. 2000). Conversely, embryos lacking Gli3 have a dorsal expansion of the intermediate neural tube (Persson et al. 2002). Furthermore, in embryos lacking all Gli gene expression the organization of the ventral neural tube is severely disrupted (Bai et al. 2004; Lei et al. 2004). In these embryos the most ventral cell types are missing and the spatially segregated gene expression patterns of the ventral neural tube lost. Consequently distinct cell types are no longer generated solely at their characteristic positions, resulting in an extensively intermingled distribution of different neuronal subtypes along the dorsal-ventral axis of the neural tube. Together these data indicate that the dorsal-ventral patterning of the ventral spinal cord depends on Gli proteins.

Although these studies provide evidence of an important role for Gli proteins in Shh-mediated patterning of the ventral neural tube, the way that this is achieved is not clear. Whether Gli dependent transcription is sufficient to account for all the patterning activity of Shh signaling remains to be determined. Moreover, how the extracellular gradient of Shh is transduced by Gli proteins to control differential gene expression is not understood. Here we present evidence that a gradient of Gli transcriptional activity is sufficient to orchestrate patterning of the neural tube even in the absence of ongoing Shh signaling. Our analysis indicates that the incremental changes in Shh concentration that are necessary to switch between alternative neuronal subtypes in the neural tube can be mimicked by similarly small changes in the level of Gli activity. Moreover, our data suggest that the duration of Shh signaling, in addition to the strength of signaling, is an important parameter directing dorsal-ventral patterning of the neural tube.

\section{Results}

\section{Activated Gli constructs generate different levels of Gli activity in vivo}

To test whether a gradient of Gli transcriptional activity is sufficient to mediate graded Shh signaling in the neural tube, we devised a method to generate different levels of Gli transcriptional activity in vivo. We focused on Gli3 since it has previously been shown that the removal of the $\mathrm{N}$-terminal repressor domain of this protein reveals transcriptional activator function (Sasaki et al. 1999). Two dominant active versions of Gli3 (Gli3A) were prepared $\left(\mathrm{Gli}_{3} \mathrm{~A}^{\Delta \mathrm{N} 1}\right.$, Gli3A ${ }^{\Delta \mathrm{N} 2}$; Fig. 1Ai; Materials and Methods) and their activities assessed in chick neural tube by in ovo electroporation. To express the constructs, a vector (pCAGGS) that generates high levels of expression from a chimeric CMV/ßActin promoter/enhancer (Niwa et al. 1991) was engineered to express bicistronically Gli3A and nuclear targeted GFP. To examine whether Gli3 $\mathrm{A}^{\Delta \mathrm{N} 1}$ or Gli3 $\mathrm{A}^{\Delta \mathrm{N} 2}$ alters the response of neural cells to Shh signaling, we tested whether the expression of either protein changes the level of expression of Ptc1, Ptc2, and Gli1-markers that have previously been used as indicators of Shh signaling (Pearse et al. 2001). Twenty-four hours after electroporation (hpt) of Hamburger Hamilton stage (HH st) 10-12 chick embryos, cells transfected with Gli3 $\mathrm{A}^{\Delta \mathrm{N} 1}$ or Gli3 $\mathrm{A}^{\Delta \mathrm{N} 2}$ exhibited a much higher level of Ptc1, Ptc2, and Gli1 expression than cells at the same dorsoventral position on the control side of the neural tube (Fig. 1B-G). This is similar to the effect of transfecting an activated Smoothened construct, SmoM2 (Hynes et al. 2000; Fig. 1H-J). These data are consistent with previous results (Sasaki et al. 1999) and suggest that Gli3A ${ }^{\Delta \mathrm{N} 1}$ or Gli3 $\mathrm{A}^{\Delta \mathrm{N} 2}$ act as dominant active Gli proteins and can mediate $\mathrm{Shh}$ responses.

We noticed that cells transfected with $\mathrm{Gli}_{3} \mathrm{~A}^{\Delta \mathrm{N} 2}$ appeared to consistently express higher levels of Ptc1, Ptc2, and Gli1 than those transfected with Gli3A ${ }^{\Delta \mathrm{N} 1}$. This raised the possibility that Gli3 $\mathrm{A}^{\Delta \mathrm{N} 2}$ is a stronger activator than Gli3A $\mathrm{A}^{\Delta \mathrm{N} 1}$. To test this we adapted a quantitative assay of Gli activity that uses a Firefly-luciferase reporter gene carrying eight copies of the Gli-binding site from the FoxA2 floor plate enhancer (Sasaki et al. 1997). HH st 10-12 chick embryos were coelectroporated with this reporter (GBS-Luc), a Renilla-luciferase driven by the CMV immediate early enhancer promoter and either Gli3A $^{\Delta \mathrm{N} 1}$ or Gli3A ${ }^{\Delta \mathrm{N} 2}$. At $24 \mathrm{hpt}$ the level of Fireflyluciferase was measured in neural cells and normalized by comparison with level of Renilla Luciferase activity. Both Gli3A $^{\Delta \mathrm{N} 1}$ and Gli3 $\mathrm{A}^{\Delta \mathrm{N} 2}$ activated the GBS-Luc reporter (Fig. $1 \mathrm{~K}$ ); however Gli3 $\mathrm{A}^{\Delta \mathrm{N} 1}$ consistently induced two- to threefold lower levels of activity than Gli3 $\mathrm{A}^{\Delta \mathrm{N} 2}$ $(n=8)$. Similar results were obtained by assaying the activity of Gli3 $\mathrm{A}^{\Delta \mathrm{N} 1}$ and Gli3 $\mathrm{A}^{\Delta \mathrm{N} 2}$ in cell lines (data not shown).

To extend the range of activity generated by the activated Gli constructs, we sought to generate lower levels 
Stamataki et al.

Figure 1. Activated Gli constructs generate different levels of Gli transcriptional activity in vivo. Gli activators up-regulate expression of Shh target genes. (Ai) Gli activator constructs were generated by deleting part $\left(\mathrm{Gli}^{\Delta \mathrm{N} 1}\right)$ or all $\left(\mathrm{Gli}^{\Delta \mathrm{N} 2}\right)$ of the $\mathrm{N}$-terminal/repressor domain of human Gli3 (hGli3). Diagram summarizing hGli3, Gli3 ${ }^{\Delta \mathrm{N} 1}$, and Gli3 ${ }^{\Delta \mathrm{N} 2}$. (ZF) Zinc finger DNAbinding domain; (N-term Rep) region of Gli3 N-terminal of the DNA-binding domain implicated in repressing transcription; (C-term Act) putative transcriptional activation domain C-terminal of the zinc finger domain; (Myc) five repeats of Myc epitope. (Aii) Gli3 ${ }^{\Delta \mathrm{N} 2}$ expressed using two different vectors, pECE and pCAGGS. Quantification of protein levels in indicated chick neural cells transfected with pECE-Gli3A $\mathrm{A}^{\Delta \mathrm{N} 2}$ had approximately fivefold lower levels of Gli3A ${ }^{\Delta \mathrm{N} 2}$ than cells in embryos electroporated with pCAGGS$\mathrm{Gli}^{\mathrm{AN} 2}$. Graph Aii shows the relative Myc immunoreactivity (average intensity of fluorescence per pixel), indicating the levels of Myc-tagged Gli3 ${ }^{\Delta \mathrm{N} 2}$ protein \pm SEM in the nuclei of neural tube cells of chick embryos electroporated with pCAGGS-Gli3 ${ }^{\Delta \mathrm{N} 2}$ and pECE-Gli3 ${ }^{\Delta \mathrm{N} 2}$. pECE-Gli3A ${ }^{\Delta \mathrm{N} 2} \sigma=0.007$; pCAGGSGli3A $^{\Delta \mathrm{N} 2} \sigma=0.037 ;\left(^{\star \star}\right)$ Student's $t$-test: $P=1.63 \times$ $10^{-10}$. (Aiii) pCAGGS-Gli3A ${ }^{\Delta \mathrm{N} 2}$, pCAGGS-Gli3A ${ }^{\Delta \mathrm{N} 1}$, and $\mathrm{pECE}-\mathrm{Gli} 3 \mathrm{~A}^{\Delta \mathrm{N} 2}$ were named according to their efficacy in the in vivo luciferase assay Gli3 $\mathrm{A}^{\mathrm{HIGH}}$, Gli3A ${ }^{\mathrm{MED}}$, and Gli3A ${ }^{\mathrm{LOW}}$, respectively. $(B-J)$ Electroporation with Gli3A $\mathrm{AIGH}^{\mathrm{HI}}$ Gli3 $\mathrm{A}^{\mathrm{MED}}$, and SmoM2, a constitutively active form of Smoothened, results in the up-regulation of Hh signaling targets Ptc1, Ptc2, and Gli1 on the transfected side of the neural tube. $\mathrm{HH}$ st 10-12 embryos were electroporated with Gli3A ${ }^{\text {HIGH }}(B-$
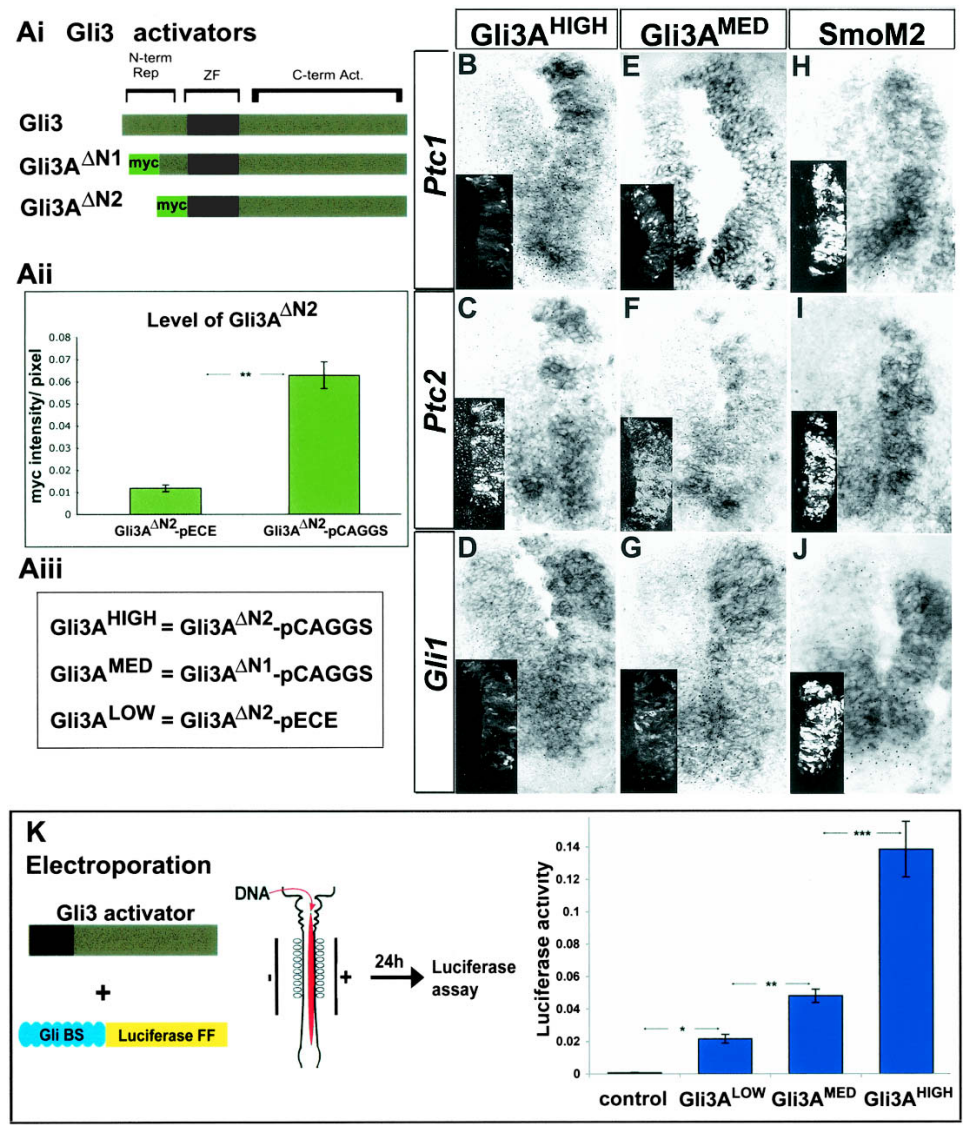
$D)$, Gli3A ${ }^{\mathrm{MED}}(E-G)$, or SmoM2 $(H-J)$ and assayed $24 \mathrm{~h}$ later for the expression of Ptc1 $(B, E, H), \operatorname{Ptc} 2(C, F, I)$, and $G l i 1(D, G, J)$. All sections are from the forelimb and anterior thoracic region of transfected embryos. Electroporated side is on the right and electroporation efficiency is indicated either by Myc immunofluorescence $\left(B-G\right.$, insets) or by GFP immunofluorescence $(H-J$, insets $) .(K) G_{\text {Gli3 }}{ }^{\mathrm{LOW}}$, Gli3A ${ }^{\mathrm{MED}}$, and Gli3 $\mathrm{A}^{\mathrm{HIGH}}$ generate low, moderate, and high levels of transcriptional activity in vivo. HH st 10-12 embryos were electroporated with each activator together with the reporter construct containing eight repeats of the Gli-binding site (Sasaki et al. 1997) and normalization plasmid, and assayed $24 \mathrm{~h} \mathrm{later} \mathrm{for}$ Luciferase activity. Graph shows the Luciferase activity of Gli3A ${ }^{\text {LOW }}$, Gli3A ${ }^{\text {MED }}$, and Gli3A ${ }^{\text {HIGH }} \pm$ SEM. Gli3A ${ }^{\text {LOW }} \sigma=0.008$;

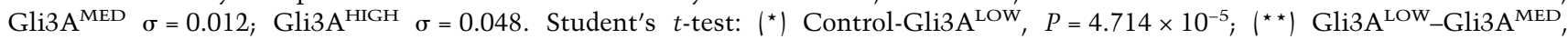
$\left.P=0.0002 ;{ }^{* \star \star}\right)$ Gli3A ${ }^{\mathrm{MED}}-\mathrm{Gli} 3 \mathrm{~A}^{\mathrm{HIGH}}, P=0.001$.

of Gli activity using a different expression vector. We found that the mammalian expression vector pECE (Ellis et al. 1986), which contains an early SV40 promoter, directs significantly lower levels of expression in chick neural tube cells than pCAGGS (Fig. 1Aii; M. Cheung, pers. comm.). Consistent with this, we found that neural cells transfected with Gli3 $\mathrm{A}^{\Delta \mathrm{N} 2}$ expressed from $\mathrm{pECE}$ contained four- to sixfold lower levels of Gli3 $\mathrm{A}^{\Delta \mathrm{N} 2}$ protein in the nucleus (Fig. 1Aii) and five- to sevenfold lower levels of GBS-Luc reporter activity than cells transfected with pCAGGS-Gli3A ${ }^{\Delta \mathrm{N} 2}$ and two- to threefold lower GBS-Luc reporter activity than $\mathrm{Gli}^{\Delta \mathrm{A}^{\Delta \mathrm{N} 1}}$ transfectants (Fig. $1 \mathrm{~K}$ ). Together, these constructs pCAGGSGli3A $^{\Delta \mathrm{N} 2}$, pCAGGS-Gli3A ${ }^{\Delta \mathrm{N} 1}$, and pECE-Gli3A ${ }^{\Delta \mathrm{N} 2}$ provide the means to generate a range of Gli transcriptional activity that differ by increments of two- to threefold and we refer to these constructs as Gli3 $\mathrm{A}^{\mathrm{HIGH}}$, Gli3A ${ }^{\mathrm{MED}}$, and Gli3 $\mathrm{A}^{\text {LOW }}$, respectively (Fig. 1Aiii).
High levels of Gli activity induce the most ventral cell types in the neural tube

To examine whether Gli activity is sufficient to mediate dorsal-ventral patterning of the ventral neural tube, we assayed the expression of progenitor domain and neuronal subtype markers in embryos transfected with each Gli3A construct. To allow informative comparisons between constructs and transfected embryos, we have standardized the conditions used in these experiments: $\mathrm{HH}$ st 11-12 embryos were electroporated with each construct and incubated for $48 \mathrm{~h}$ and analysis was restricted to the forelimb and anterior thoracic regions. For clarity and based on our previous study (Persson et al. 2002), we have divided the spinal cord into four territories: Region A encompasses the floor plate and progenitors (p) of V3 neurons; Region B comprises $\mathrm{pMN}$ and $\mathrm{p} 2$ that generate motor neurons (MNs) and V2 neurons; Region $\mathrm{C}$ in- 
cludes p1, p0, dI6 that express Dbx2; and Region D contains the progenitor domains dI5-dI1 dorsal to the domain of Dbx2 expression (Fig. 2).

First we focused on Region A. Floor plate is marked by FoxA2 expression while p3 and their progeny, V3 neurons, express Nkx2.2 (Fig. 2J). Forced expression of Gli3 $\mathrm{A}^{\mathrm{HIGH}}$ resulted in the ectopic expression of FoxA2

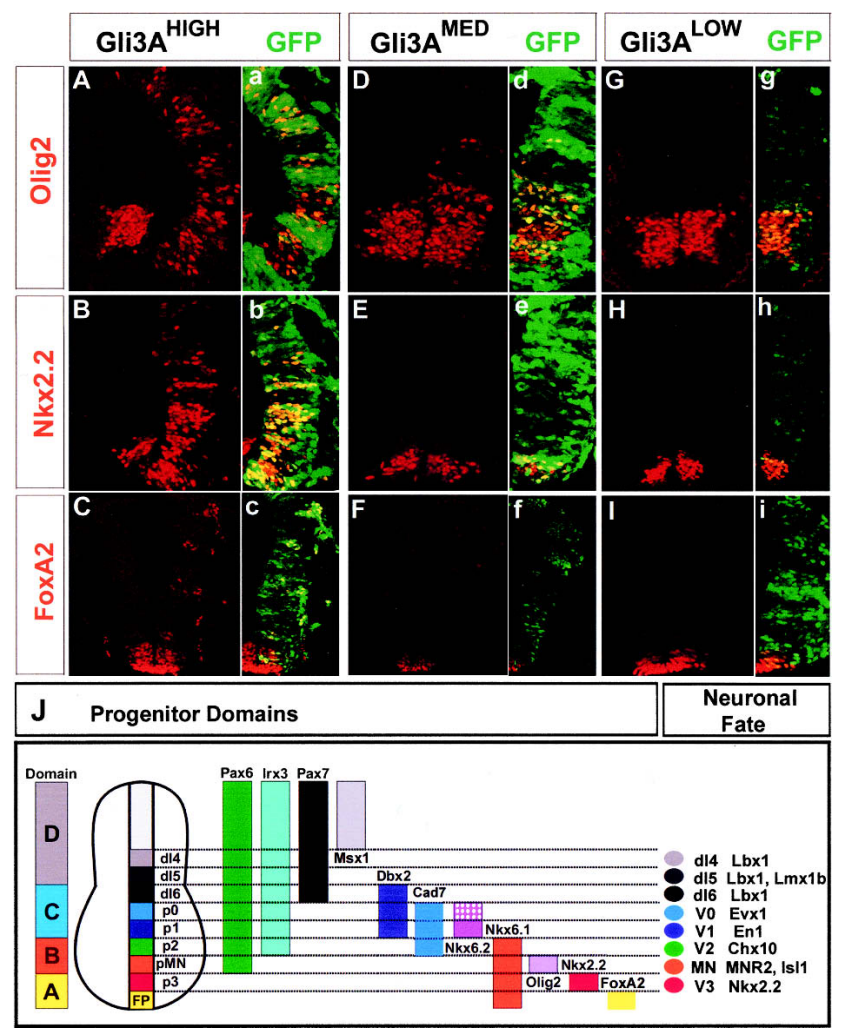

Figure 2. High levels of Gli transcriptional activity induce Region A markers. Different levels of Gli transcriptional activity induce different sets of ventral neural markers. Gli3 $\mathrm{A}^{\mathrm{HIGH}}$ electroporation induced ectopic expression of the two most ventral identities, p3 progenitors and floor plate cells (FP). Gli3 $\mathrm{A}^{\mathrm{MED}}$ electroporation induced $\mathrm{MN}$ progenitors but not $\mathrm{p} 3$ or FP. Gli3A $^{\text {LOW }}$ did not induce the three most ventral cell types (pMN, p3, FP). HH st 11-12 embryos were electroporated in ovo with Gli3A ${ }^{\mathrm{HIGH}}(A-C)$, Gli3A ${ }^{\mathrm{MED}}(D-F)$, and Gli3A ${ }^{\mathrm{LOW}}(G-I)$ and assayed $48 \mathrm{~h}$ later for the expression of the indicated genes. All sections are from the forelimb and anterior thoracic region of embryos. (a-i) Overlay of green channel (GFP), indicating electroporated regions of the neural tube, with red channel $(A-I)$ marking expression of Olig2 $(A, D, G), \mathrm{Nkx} 2.2(B, E, H)$, and FoxA2 $(C, F, I) .(A-C)$ Olig2 $(A), \operatorname{Nkx} 2.2(B)$, and FoxA2 $(C)$ were ectopically expressed in dorsal and intermediate regions of neural tube electroporated with Gli3A ${ }^{\mathrm{HIGH}}$. $(D-F)$ Olig2 $(D)$, but not Nkx2.2 $(E)$ or FoxA2 $(F)$ were induced in Gli3A ${ }^{\mathrm{MED}}$-transfected cells. $(G-I)$ Olig2 $(G), \operatorname{Nkx2} 2(H)$, and FoxA2 $(I)$ were restricted to their normal regions of expression in Gli3 $\mathrm{A}^{\mathrm{LOW}}$ electroporated neural tubes. Note that both Gli3 $\mathrm{A}^{\mathrm{HIGH}}$ and Gli3A $\mathrm{A}^{\mathrm{MED}}$ produced a noticeable increase in proliferation on the transfected side of electroporated neural tubes. (J) Summary indicating the relationship between progenitor proteins and neuronal subtype identity. and Nkx2.2 throughout the dorsal-ventral axis (Fig. 2B,C) and the repression of Pax6 (Fig. 3B). Cells expressing markers of Region A in ectopic positions coexpressed GFP and the Myc5 epitope present in Gli3 $\mathrm{A}^{\mathrm{HIGH}}$, indicating the effects of Gli3 $\mathrm{A}^{\mathrm{HIGH}}$ were cell-autonomous (data not shown). Not all progenitor cells that expressed Gli3A $^{\text {HIGH }}$ coexpressed either Nkx2.2 or FoxA2 (Fig. 2B, C; see below).

In contrast, ectopic expression of $\mathrm{Gli}_{3} \mathrm{~A}^{\mathrm{LOW}}$ and Gli3A $^{\text {MED }}$ was not sufficient to induce FoxA2 or Nkx2.2 in the intermediate neural tube (Fig. 2E,F,H,I). However, cells transfected with Gli3A $\mathrm{A}^{\mathrm{MED}}$ contained decreased levels of Pax6 (Fig. 3H). The expression of Gli3 $\mathrm{A}^{\mathrm{LOW}}$ and Gli3A ${ }^{M E D}$ in the most dorsal region of the neural tube adjacent to the roof plate occasionally resulted in a small number of ectopic FoxA2-expressing cells (data not shown) - this is a region of the neural tube that has previously been characterized as more competent than other areas for floor plate induction (Ruiz i Altaba et al. 1995). These data are consistent with the idea that Gli3A ${ }^{\text {LOW }}$ and Gli3A $\mathrm{A}^{\text {MED }}$ have activator function, but neither Gli3 ${ }^{\text {MED }}$ nor Gli3 $A^{\text {LOW }}$ has sufficient activity to induce ectopic FoxA2 or Nkx2.2 in the intermediate neural tube. Together these data indicate that a high level of Gli activity is sufficient to reprogram intermediate neural tube cells to express markers characteristic of Region A.

\section{Moderate levels of Gli activity induce motor neurons}

We next turned our attention to Region $\mathrm{B}$, which encompasses progenitors that express Olig2, MNR2/HB9, and Nkx6.1 but not Pax7 and generates MNs and V2 neurons (Fig. 2J). Consistent with the ability of Gli3A ${ }^{\mathrm{HIGH}}$ to induce ventral neural tube identities, mosaic expression of Gli3A $^{\mathrm{HIGH}}$ in cells situated dorsal to Region B resulted in the cell-autonomous ectopic expression of Olig2, MNR2/HB9, and Nkx6.1 and repression of Pax7 and Irx3 (Figs. 2A, 3A,C,D,F). It was noticeable however, that, in general, the transfected cells that expressed Region $B$ markers expressed lower levels of Gli3 $\mathrm{A}^{\mathrm{HIGH}}$ than the cells expressing Region A markers (Fig. 2; see below). Within Region B itself, expression of high levels of Gli3 $\mathrm{A}^{\mathrm{HIGH}}$ appeared to cause the cell-autonomous extinction of expression of both Olig2 and MNR2/HB9 (Figs. 2A, 3F). This correlated with the ectopic expression of Nkx2.2 and FoxA2 in this region (Fig. 2B,C), indicating that these cells had acquired a more ventral identity.

In contrast to the inability of $\mathrm{Gli}^{3} \mathrm{~A}^{\mathrm{MED}}$ to induce Region A markers, Region $\mathrm{B}$ fates were induced by ectopic expression of Gli3 $\mathrm{A}^{\mathrm{MED}}$ in the intermediate neural tube. Mosaic expression of Gli3A $\mathrm{A}^{\mathrm{MED}}$ resulted in the cell-autonomous induction of Olig2 (Fig. 2D) and Nkx6.1 (Fig. 3J) and the repression of the dorsal marker Pax7 (Fig. 3G). In addition, many Gli3 $\mathrm{A}^{\mathrm{MED}}$-transfected cells contained low levels of Pax6 and had repressed expression of Irx3 (Fig. 3H,I). Consistent with the progenitor code induced by Gli3A ${ }^{M E D}$, transfected embryos contained ectopic $\mathrm{MNs}$ and V2 neurons identified by MNR2/HB9 and 


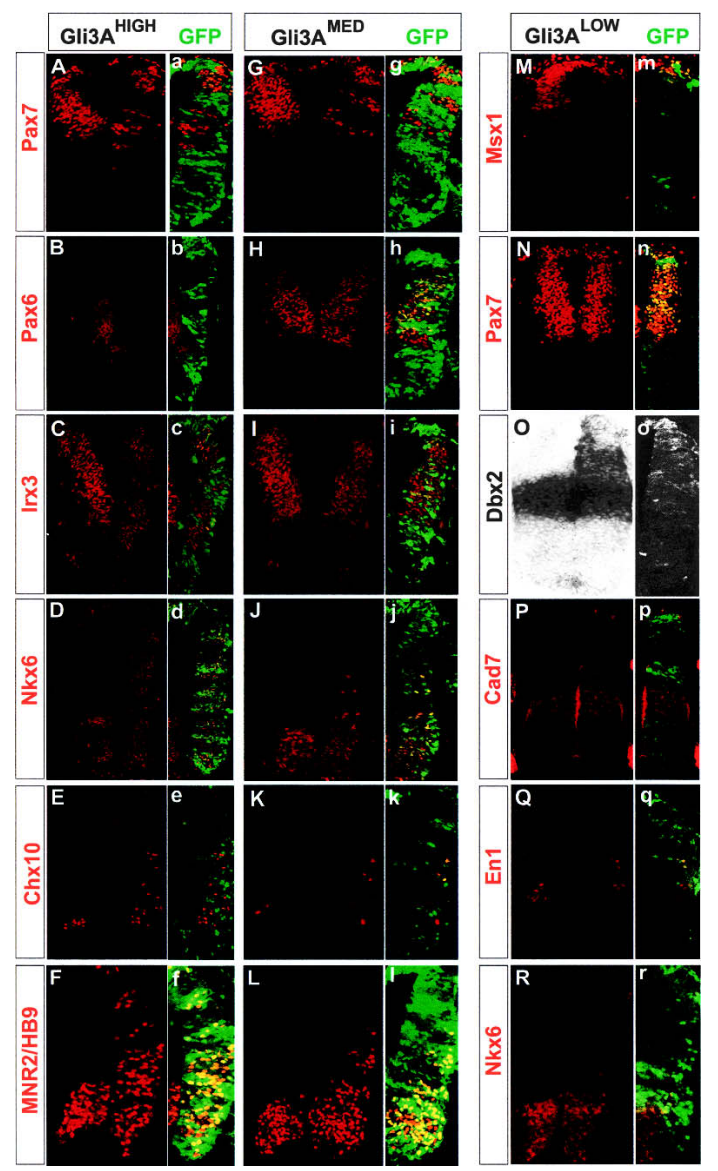

Figure 3. Moderate levels of Gli transcriptional activity induce MNs, and low levels of Gli activity induce cell fates characteristic of the intermediate neural tube. In addition to Region $\mathrm{A}$ markers, Gli3 $\mathrm{A}^{\mathrm{HIGH}}$ induces MNs and V2 neurons. Gli3 $\mathrm{A}^{\mathrm{MED}}$ was sufficient to induce MNs and V2 neurons while Gli3 $\mathrm{A}^{\mathrm{LOW}}$ induces intermediate neural cell types. $\mathrm{HH}$ st 11-12 embryos were electroporated in ovo with Gli3 $\mathrm{A}^{\mathrm{HIGH}}(A-F)$, Gli3 $\mathrm{A}^{\mathrm{MED}}$ $(G-L)$, and Gli3 $\mathrm{A}^{\mathrm{LOW}}(M-R)$ and assayed $48 \mathrm{~h}$ later for the expression of the indicated genes. All sections are from the forelimb and anterior thoracic region of the embryos. $(a-n, p-r)$ Overlay of green channel (GFP), indicating electroporated regions of the neural tube, with red channel $(A-N, P-R)$ marking expression of the indicated markers. (o) GFP immunofluorescence indicating the electroporated cells of the $D b \times 2$ hybridized section. $(A, G)$ Pax7 is down-regulated in both Gli3 $\mathrm{A}^{\mathrm{HIGH}}$ and Gli3A $^{\text {MED }}$ electroporated cells. There are a small number of Pax7-expressing cells ventral to the normal boundary of expression; this may be a consequence of up-regulation of Ptc (Fig. 1) causing a nonautonomous induction of $\operatorname{Pax} 7$ (Briscoe et al. 2001). $(B, C, H, I) \operatorname{Pax} 6(B, H)$ and Irx3 $(C, I)$ are down-regulated in

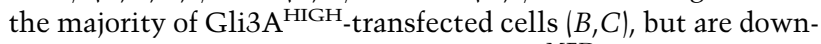
regulated only in a proportion of $\mathrm{Gli} 3 \mathrm{~A}^{\mathrm{MED}}$-transfected cells $(H, I) .(D-F, I-L) \operatorname{Nkx} 6(D, J), \operatorname{Chx} 10(E, K)$, and MNR2/HB9 $(F, L)$ are ectopically expressed by Gli3A $\mathrm{A}^{\mathrm{HIGH}}(D-F)$ and Gli3A $\mathrm{A}^{\mathrm{MED}}$ $(J-L)$ electroporated cells. $(M)$ Msx1 is down-regulated in Gli3 $\mathrm{A}^{\text {LOW }}$-expressing cells. $(N)$ Pax7 is largely unaffected. In a small number of Gli3A ${ }^{\text {LOW }}$ electroporated cells Pax7 is downregulated. $(O-R)$ Gli3 ${ }^{\text {LOW }}$ electroporation causes the ectopic expression of $D b x 2(O), \operatorname{Cad} 7(P), \operatorname{En} 1(Q)$, and $N k x 6(R)$ in regions dorsal to their normal boundaries of expression. Note that a monoclonal anti-GFP antibody is used in $e, k$, and $q$ that does not readily detect low levels of GFP expression.
Chx10 expression, respectively (Fig. 3K,L). These data suggest that in comparison to Gli3 $\mathrm{A}^{\mathrm{HIGH}}$ the twoto threefold lower levels of Gli activity provided by Gli3A $^{\text {MED }}$ are sufficient to induce MNs and V2 neurons but not Region A fates.

\section{Low levels of Gli activity induce intermediate neural} tube fates

To address whether lower levels of Gli activity had an effect on neural tube patterning, we analyzed embryos transfected with Gli3 ${ }^{\text {LOW }}$. This construct did not induce Olig2 or markers of post-mitotic MN identity (Fig. 2G; data not shown). Ectopic Nkx6.1 (Fig. 3R) expression in the intermediate neural tube was occasionally observed in Gli3 $\mathrm{A}^{\text {LOW }}$ transfected embryos. The expression of Nkx6.1 in the absence of pMN markers is indicative of p2 identity, consistent with this, ectopic V2 neurons were occasionally observed (data not shown). Thus a lower level of Gli activity appears to be required for V2 neuron production than for $\mathrm{MN}$ induction.

We next examined markers of Region C in Gli3A ${ }^{\text {LOW }}$ transfectants. Region $\mathrm{C}$ comprises the intermediate neural tube that contains the progenitors of $\mathrm{V} 1, \mathrm{~V} 0$, and dI6 neurons. This domain is ventral to Msx expression and encompasses progenitors that express Dbx2 and Cad7; the dorsal half of this region expresses Pax7 (Fig. 2J). Forced expression of Gli3A ${ }^{\text {LOW }}$ induced expression of Dbx2 and Cad7 in Region D (Fig. 3O,P). Concomitantly Gli3A $^{\text {LOW }}$ repressed Msxl (Fig. 3M) while Pax7 expression was repressed in some but not all Gli3 $\mathrm{A}^{\mathrm{LOW}}$-expressing cells (Fig. 3N). Progenitors expressing Dbx2 in the absence of Pax7 generate V1 and V0 neurons; consistent with this, ectopic generation of $\mathrm{V} 1$ and $\mathrm{V} 0$ neurons in more dorsal positions was observed in Gli3 ${ }^{\text {LOW }}$ transfected embryos (Fig. 3Q; data not shown). Together these data indicate that low levels of Gli activity are sufficient to induce characteristics of the intermediate neural tube in more dorsal regions of the neural tube. Overall, the data support the idea that a gradient of Gli activity simulates graded Shh signaling.

\section{Activator Gli proteins function independent of ongoing Shh signaling}

We next tested the idea that the Gli3A constructs are sufficient to mediate Shh responses in the absence of ongoing Shh signaling. In particular, the induction of the floor plate marker FoxA2 by Gli3A $\mathrm{HIGH}^{\mathrm{HI}}$ raised the possibility that Shh induction was responsible for the activities attributed to this construct. In ovo electroporation of Gli3 $\mathrm{A}^{\mathrm{HIGH}}$, Gli3 $\mathrm{A}^{\mathrm{MED}}$ and Gli3A $\mathrm{A}^{\text {LOW }}$ did not alter Shh expression at $24 \mathrm{hpt}$ (data not shown). At $48 \mathrm{hpt}$, neither Gli3A ${ }^{\text {MED }}$ nor Gli3 $\mathrm{A}^{\text {LOW }}$ induced Shh expression in ventral or intermediate regions of the neural tube. In contrast, expression of Gli3A ${ }^{\mathrm{HIGH}}$ resulted in a small number of cells ectopically expressing Shh (data not shown); this is consistent with the observed induction of FoxA2 (Fig. 2C). To rule out the possibility that ectopic 
Shh expression mediated the induction of ventral markers, we analyzed embryos that had been coelectroporated with Gli3 $\mathrm{A}^{\mathrm{HIGH}}$ or Gli3A $\mathrm{A}^{\mathrm{MED}}$ and the extracellular inhibitor of Shh signaling, Hedgehog interacting protein (HIP) (Chuang and McMahon 1999). Expression of HIP on its own resulted in the repression of ventral progenitor identity and cell fate and the ventral expansion of markers of dorsal identities (Fig. 4I-L; data not shown). Coelectroporation of Gli3 $\mathrm{A}^{\mathrm{HIGH}}$ and HIP did not affect the activity of Gli3 $\mathrm{A}^{\mathrm{HIGH}}$. In cotransfected embryos, Gli3A $^{\mathrm{HIGH}}$ expression resulted in the cell-autonomous induction of FoxA2, Nkx2.2, and Olig2 and repression of Pax7 (Fig. 4A-D) while adjacent untransfected cells displayed the nonautonomous HIP-induced ventral-to-dorsal shift, evidenced by ectopic Pax7 expression (Fig. 4A). Similarly the activity of Gli3A $\mathrm{A}^{\mathrm{MED}}$ was unaffected by coelectroporation with HIP; Gli3 ${ }^{\text {MED }}$-transfected cells expressed Olig2 and repressed Pax7 (Fig. 4E,F). Moreover, ectopic V1 and V0 neurons were induced in embryos transfected with Gli3 $\mathrm{A}^{\mathrm{LOW}}$ and HIP (data not shown).
HIP functions as an extracellular inhibitor of Shh signaling; the possibility exists therefore that in transfected cells, low-level Shh signaling or a blunted gradient of Shh activity remains. As an alternative to HIP, we examined whether the Gli3A constructs induce Shh responses in the presence of $\mathrm{mPtc}^{\Delta \mathrm{loop} 2}$, a cell-autonomous dominant inhibitor of Shh signaling (Briscoe et al. 2001). Neural cells transfected with either Gli3A ${ }^{\mathrm{HIGH}}$ or Gli3A $^{\mathrm{MED}}$ and $\mathrm{mPtc1}^{\text {sloop2 }}$ behave the same as cells transfected with Gli3A constructs alone (Fig. 4M-T; data not shown). $\mathrm{mPtcl}^{\Delta \text { loop} 2 / G l i 3} \mathrm{~A}^{\mathrm{HIGH}}$ transfection resulted in the ectopic expression of Region A and B markers while $\mathrm{mPtcl}^{\Delta \mathrm{loop} 2} / \mathrm{Gli}^{\mathrm{A}} \mathrm{A}^{\mathrm{MED}}$ transfection induced Region B markers. Together these data support the idea that the effects of the Gli3A constructs are cell-autonomous and not the result of an increased provision of Shh by the floor plate or ectopic induction of Shh expression. Moreover, the activity of the Gli3A constructs does not require ongoing Shh signaling in neural cells, indicating that Gli activity is sufficient to mediate the full reper-
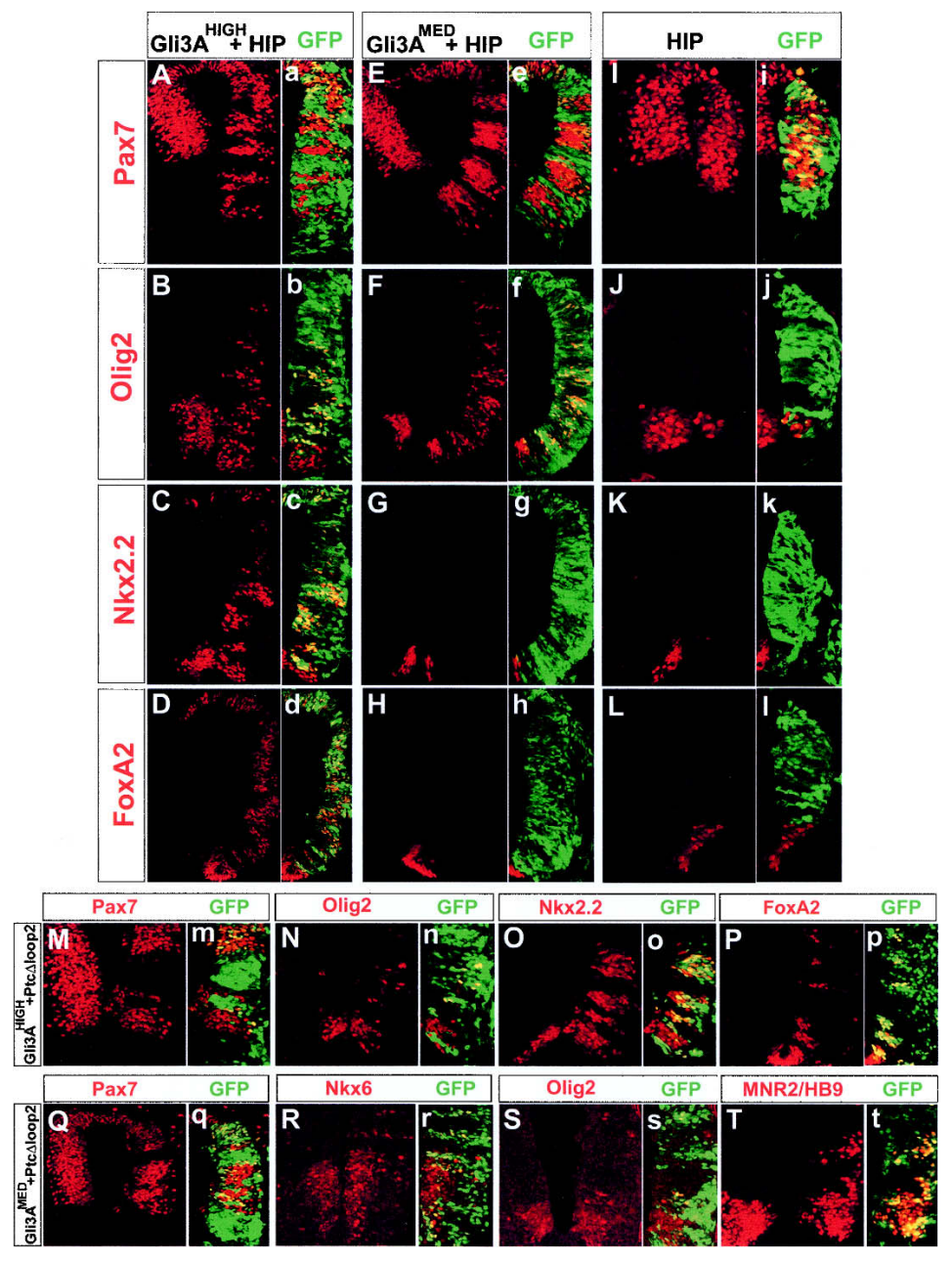

$(R)$, Olig2 $(S)$, and MNR2/HB9 $(T)$ are ectopically expressed dorsal to their normal boundaries in embryos transfected with Gli3A ${ }^{\mathrm{MED}}$ and $\mathrm{mPtc}^{\Delta \text { loop2}}$. The cotransfection of Gli3 $\mathrm{A}^{\mathrm{HIGH}} / \mathrm{Gli}^{\mathrm{AMED}}$ and $\mathrm{mPtc}^{\text {sloop2}}$ are carried out at a ratio of $1: 3$ (Gli:Ptc) to ensure that the majority of transfected cells receive $\mathrm{mPtc}^{\Delta \mathrm{Lloo}^{2}}$. In addition, $\mathrm{mPtc} 1^{\Delta \mathrm{loop} 2}$ is expressed along with GFP using a bicistronic vector (Briscoe et al. 2001); therefore GFP expression is not an indication of Gli3A expression. 
toire of ventral patterning responses associated with graded Shh signaling.

\section{The level of Gli activity correlates with changes in neuronal patterning}

Transfection of each Gli3A construct resulted in the induction of genes corresponding to more than one of the defined progenitor domains (Figs. 2, 3). One possibility that could account for these data is that ectopic expression of the Gli3A constructs resulted in the specification of cell types with mixed identities such that individual transfected cells expressed combinations of genes not normally encountered in vivo. However, analysis of Gli3 $\mathrm{A}^{\mathrm{HIGH}}$-transfected cells indicated that markers of $\mathrm{MN}$ and Region A were not expressed in the same cells (Fig. 5B; data not shown). Moreover, ventral markers were not coexpressed with markers characteristic of the dorsal neural tube (Fig. 5A). In contrast, $20 \%-30 \%$ of Gli3 $\mathrm{A}^{\mathrm{HIGH}}$-transfected cells coexpressed the Region A markers Nkx2.2 and FoxA2 (Fig. 5C). This is consistent with expression of Nkx2.2 in floor plate cells at early developmental stages (Ericson et al. 1997a) and the ability of Nkx2.2 to induce FP and FoxA2 expression (M. Persson and J. Ericson, pers. comm.). In embryos transfected with Gli3A $\mathrm{A}^{\mathrm{MED}}$ or Gli3 $\mathrm{A}^{\mathrm{LOW}}$, progenitor and neuronal subtype gene expression codes remained distinct and intact (Fig. 5D,E; data not shown). Together these data suggest that activation of Gli-mediated transcription is sufficient to faithfully recapitulate Shh signaling and does not result in the generation of cells with confused or mixed identities.

An alternative explanation for the multiple progenitor domain markers and neuronal subtypes generated by each Gli3A construct is that this is a consequence of the different levels of transfected protein in individual cells, resulting from the stochastic nature of in ovo electroporation. If this were the case, then the amount of Gli3A protein in a cell should correspond with the genes being expressed in that cell. To test this possibility, we took advantage of the Myc5 tag present in the Gli3 ${ }^{\Delta \mathrm{N} 2}$ to quantify the level of protein in individual transfected cells. Cells transfected with Gli3 $\mathrm{A}^{\text {LOW }}$ contained approximately sixfold lower levels of GBS-Luc activity than cells transfected with Gli3 $\mathrm{A}^{\mathrm{HIGH}}$; consistent with this, Gli3 $\mathrm{A}^{\mathrm{LOW}}$-transfected cells contained approximately four- to sixfold lower levels of Gli3 $\mathrm{A}^{\Delta \mathrm{N} 2}$ protein in the nuclei than cells in embryos electroporated with Gli3A ${ }^{\mathrm{HIGH}}$ (Figs. 1Aii, 5F). We extended this analysis in embryos transfected with Gli3 $\mathrm{A}^{\mathrm{HIGH}}$. We divided transfected cells into a group that expressed Nkx2.2 and a group that expressed Olig2. We found that the levels of Gli3 ${ }^{\Delta \mathrm{N} 2}$ were $\sim 50 \%$ higher in cells expressing ectopic Nkx2.2 than in cells expressing Olig2 (Fig. 5F). These data are consistent with the idea that the multiple progenitor identities induced by each Gli3A construct reflect the level of activity in individual cells. Moreover,

Figure 5. The level of Gli activity correlates with changes in neuronal patterning. Gli activity is sufficient to faithfully recapitulate Shh signaling, as transfected cells do not coexpress markers characteristic of different progenitor domains or neuronal subtypes. In addition, ectopic Nkx2.2 cells have a higher amount of Gli activator in the nucleus compared with the ectopic Olig2 cells. HH st 11-12 embryos were electroporated in ovo with Gli3 $\mathrm{A}^{\mathrm{HIGH}}(A-$ $C, F)$ or Gli3A $\mathrm{A}^{\mathrm{MED}}(D, E)$ and assayed $24 \mathrm{~h}$ or $48 \mathrm{~h}$ later for the expression of the indicated genes. All sections are from the forelimb and anterior thoracic region of the embryos. (Ai-Aiii) Pax7 is down-regulated in Gli3 $\mathrm{A}^{\mathrm{HIGH}}$ electroporated cells and Pax7 is not coexpressed with ectopically induced Olig2. (Bi-Biii) Olig2 and Nkx2.2 are ectopically expressed in different Gli3A ${ }^{\mathrm{HIGH}}$-transfected cells. (Ci-Ciii) $\mathrm{Nkx} 2.2$ and FoxA2 expression is up-regulated in $\mathrm{Gli}_{3} \mathrm{~A}^{\mathrm{HIGH}}$-transfected cells and
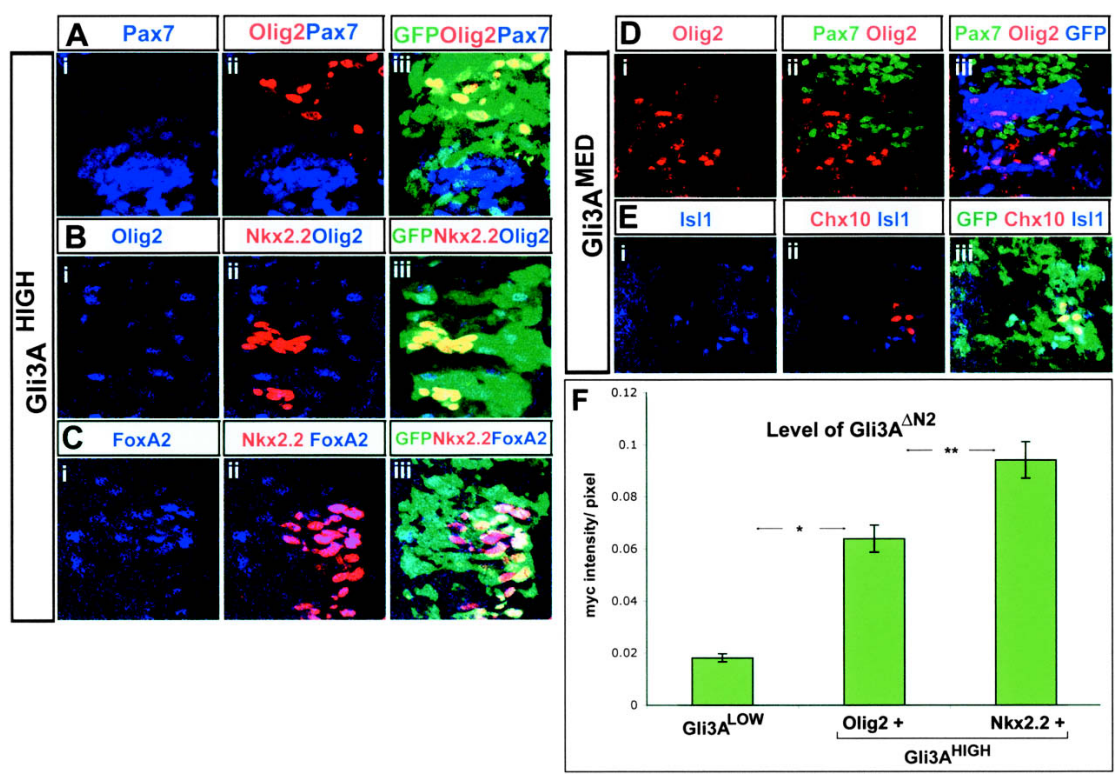

they colocalize in $\sim 25 \%$ of the ectopic Nkx2.2 positive cells. (Di-Diii) Pax7 is down-regulated by Gli3A $\mathrm{A}^{\mathrm{MED}}$ electroporated cells and is not coexpressed with ectopically induced Olig2. (Ei-Eiii) Gli3 $\mathrm{A}^{\mathrm{MED}}$-transfected cells form ectopic motor neurons (Isl1) or V2 interneurons (Chx10) and do not coexpress markers of both neuronal subtypes. (F) Quantification of Gli3A ${ }^{\Delta \mathrm{N} 2}$ protein levels in chick neural cells transfected with Gli3 $\mathrm{A}^{\mathrm{LOW}}$ or Gli3 $\mathrm{A}^{\mathrm{HIGH}}$. Graph shows the relative Myc immunoreactivity (average intensity of fluorescence per pixel \pm SEM, indicating the levels of Myc-tagged Gli3 ${ }^{\Delta \mathrm{N} 2}$ protein in the nuclei of cells. For Gli3 $\mathrm{A}^{\mathrm{HIGH}}$, cells were divided into those expressing Nkx2.2 and those expressing Olig2. On average, Nkx2.2 is expressed by cells that contain higher amounts of Gli

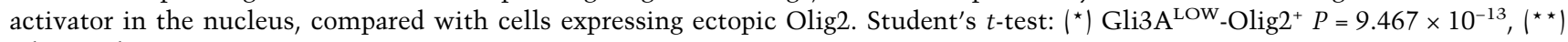
Olig2 ${ }^{+}-\mathrm{Nkx} 2.2^{+} P=0.001$. 
the data support the idea that a gradient of Gli activity is sufficient to mediate graded Shh signaling and suggest that the small changes in Shh concentration that are necessary to switch between alternative neuronal subtypes are mediated by similar small changes in the level of Gli activity.

\section{Shh signaling induces Gli activity in vivo}

The data suggest that graded Shh signaling is transposed into a gradient of Gli activity by responding cells. To detect Shh-induced Gli activity in vivo, we constructed a fluorescent reporter by replacing the Luciferase gene in the GBS-Luc plasmid with a nuclear targeted GFP to create GBS-GFP. To test whether different levels of Gli activity induce different amounts of GBS-GFP, embryos were coelectroporated with GBS-GFP and either Gli3A $^{\text {MED }}$ or Gli3A ${ }^{\mathrm{HIGH}}$. GFP could be detected in individual cells in embryos transfected with either Gli3A $^{\text {MED }}$ (Fig. 6B) or Gli3A ${ }^{\mathrm{HIGH}}$ (Fig. 6C) and the level of GFP in individual cells was consistently and markedly higher in Gli3 $\mathrm{A}^{\mathrm{HIGH}}$-expressing cells than in Gli3 $\mathrm{A}^{\mathrm{MED}}$. expressing cells. Quantitation indicated that $\mathrm{Gli}_{3} \mathrm{~A}^{\mathrm{HIGH}}$ transfected cells contained, on average, twofold higher levels of GBS-GFP fluorescence than Gli3A ${ }^{\mathrm{MED}}$-expressing cells. These data are consistent with the luciferase reporter results (Fig. 1K) and indicate that GBS-GFP represents a reporter of Gli activity that provides single cell resolution.

To test whether Shh signaling induced Gli activity in neural cells, we first examined whether cotransfection of SmoM2 was sufficient to induce GBS-GFP activity. Cells transfected with SmoM2 ectopically expressed markers of Region A and Region B (Fig. 7; data not shown); moreover, GBS-GFP activity was readily detectable in transfected embryos (Fig. 6D). We then took advantage of an explant culture approach. HH st 10 chick embryos were electroporated in ovo with GBS-GFP and intermediate [i] neural explants from electroporated embryos isolated 1-2 h later and grown in vitro (Briscoe et al. 2001) in the presence of Shh protein at a concentration sufficient to induce Nkx2.2 expression. Explants grown in the absence of Shh $(n=15$; data not shown) did not express detectable levels of GFP. In contrast, GBS-GFP expression was evident in explants grown in media containing Shh ( $n$ =9; data not shown). Together these data support the idea that Shh signaling increases Gli activity in vivo. Finally, to assay the extent of endogenous Gli activity in vivo, we examined neural tubes transfected with GBSGFP and CMV $\beta$ Gal (a transfection marker). GBS-GFP was restricted to ventral regions of the neural tube (Fig. 6A). No GBS-GFP activity was detected in the dorsal neural tube or neural crest; moreover, within ventral regions of the neural tube, cells closer to the floor plate appeared to contain the highest levels of GFP. Analysis of expression of Olig2 in embryos transfected with GBSGFP indicated that the region of the ventral neural tube in which Gli activity could be detected extended in to the MN progenitor domain (data not shown). Together these data are consistent with the idea that Shh signaling

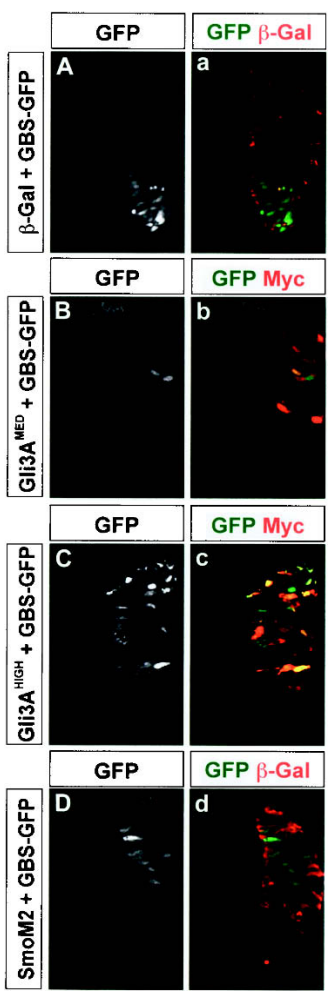

Figure 6. Shh signaling induces Gli activity in vivo. HH st 11-12 embryos were coelectroporated in ovo with the Gli-binding sites (GBS-GFP) reporter construct and $\beta$-Gal $(A)$, Gli3A ${ }^{\mathrm{MED}}$ $(B)$, Gli3A ${ }^{\text {HIGH }}(C)$, or SmoM2 and $\beta$-Gal $(D)$ and assayed $24 \mathrm{~h}$ later for the expression of GFP. $(a-d)$ Overlay of green channel (GFP) indicating Gli transcriptional activity, with red channel $(\beta-\mathrm{Gal}, a, d)$ or Myc $(b, c)$ indicating the electroporated regions of the neural tube. (A) GFP shows the endogenous Gli activity in the ventral neural tube. Cells close to the floor plate have higher GFP intensity compared with more distant ones. $(B, C)$ Both Gli3A $^{\mathrm{MED}}(B)$ and Gli3A $\mathrm{AIGH}^{\mathrm{HI}}(C)$ induce Gli transcriptional activity in the dorsal neural tube. GFP intensity is approximately twofold higher in the Gli3 $\mathrm{A}^{\mathrm{HIGH}}$ compared with Gli3 $\mathrm{A}^{\mathrm{MED}}$ electroporated cells. $(D)$ Electroporation with SmoM2 induces Gli transcriptional activity in the dorsal neural tube.

increases Gli activity in ventral regions and that progenitors of Region A and Region B are generated by increasing levels of Gli activity.

\section{Temporal integration of Shh/Gli signaling patterns the ventral neural tube}

Signal duration as well as signal strength has been proposed to be an important parameter in morphogen signaling (Gurdon and Bourillot 2001; Ahn and Joyner 2004; Harfe et al. 2004). We therefore considered whether the integration of Shh/Gli activity over time might influence ventral neural tube patterning. We reasoned that if duration of signaling is critical, increasing the time of exposure to an activating signal would result in the induction of markers of increasingly more ventral domains; conversely, decreasing the time of exposure to a 
Stamataki et al.

Figure 7. Temporal integration of Shh/Gli signaling patterns the ventral neural tube. Strength and duration of Gli activity are important for ventral neural tube patterning. HH st 11-12 embryos were electroporated in ovo with the SmoM2 $(A-C)$, Gli3A ${ }^{\mathrm{MED}}(E-H)$, or Gli3 $\mathrm{A}^{\mathrm{HIGH}}(K)$ and assayed at the indicated time points after electroporation (hpt) for the induction of Olig2 and Nkx2.2. Overlay of green channel (GFP) ( $a-$ $c, e-g)$, indicating electroporated regions of the neural tube, with red channel $(A-C, E-G)$ showing expression of the indicated markers. $(A)$ Olig2 is up-regulated by SmoM2-transfected cells 12 hpt. (B) At this time point Nkx2.2 is induced in few cells. (C) SmoM2 is sufficient to induce Nkx2.2 by 24 hpt. (D) Graph indicating GFP protein levels (green bars) in neural cells transfected with pCAGGS-GFP and GBS-Luc Luciferase activity (blue bars) after electroporation with SmoM2 at the indicated time points. GFP protein levels (green bars) do not increase during the course of the experiment and levels of Gli activity induced by SmoM2 remain constant (blue bars). $(E, F)$ Olig2 $(E)$ but not $N k x 2.2(F)$ is upregulated by Gli3A ${ }^{\mathrm{MED}}$ electroporated cells 48 hpt. $(G)$ Gli3 $^{\mathrm{MED}}$ is sufficient to induce Nkx2.2 by 72 hpt. (H) Quantitation of Olig2 and Nkx2.2 induction by Gli3 $\mathrm{A}^{\mathrm{MED}}$ at $48 \mathrm{hpt}$ and $72 \mathrm{hpt}$. (I) Quantitation of $\mathrm{Gli} 3^{\Delta \mathrm{N} 1}$ protein levels in chick neural cells at the indicated time points after electroporation with Gli3A ${ }^{\mathrm{MED}}$. Graph shows the relative Myc immunoreactivity (average in-
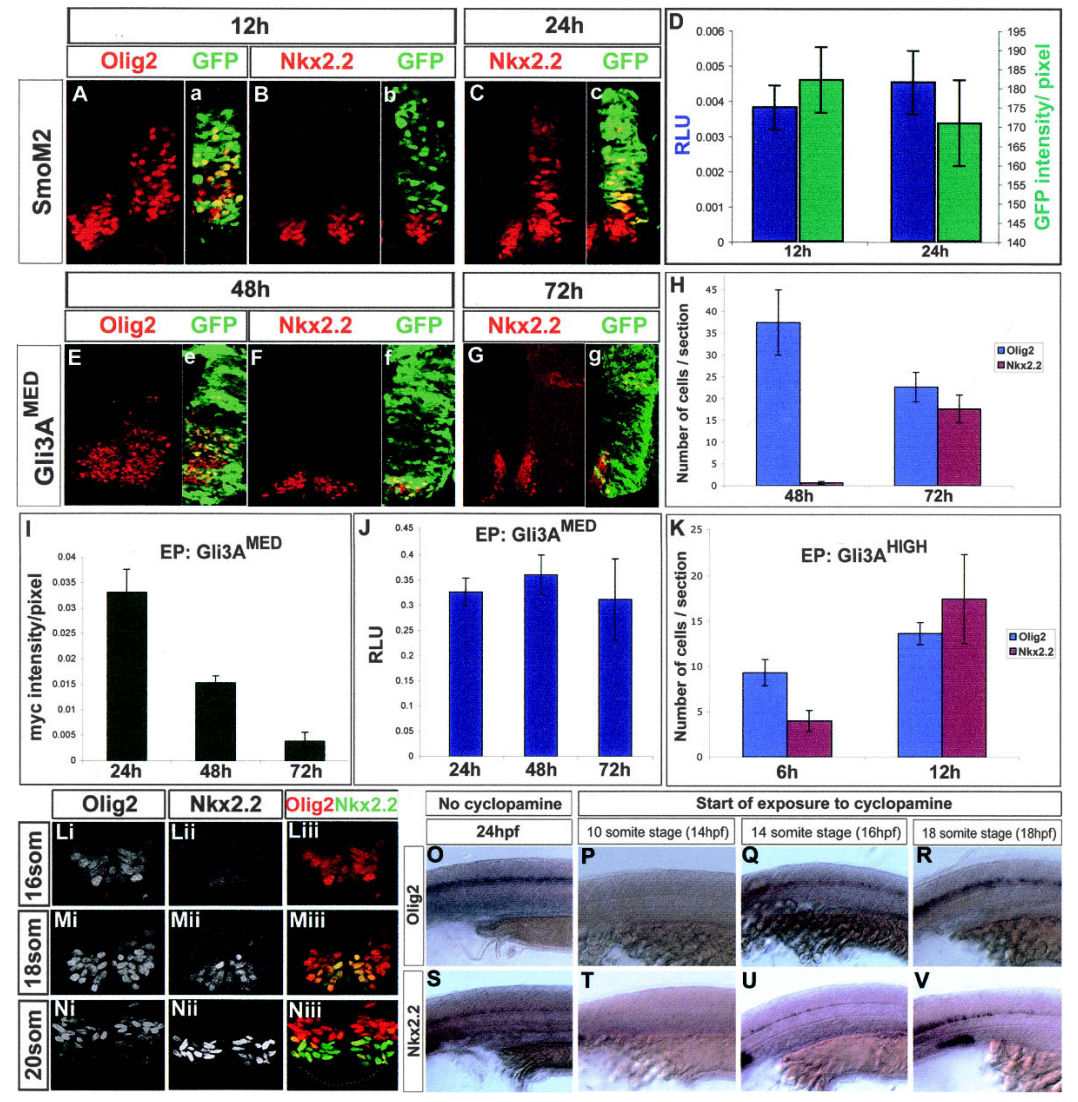
tensity of fluorescence per pixel) \pm SEM, indicat-

ing the levels of Myc-tagged Gli3 ${ }^{\Delta \mathrm{N} 1}$ protein in the nuclei of cells. $(J)$ Graph indicating GBS-Luc Luciferase activity (RLU) in neural cells at the indicated time points after electroporation with Gli3 $\mathrm{A}^{\mathrm{MED}}$. $(K)$ Quantitation of Olig2 and Nkx2.2 induction by Gli3 $\mathrm{A}^{\mathrm{HIGH}}$ at $6 \mathrm{hpt}$ and $12 \mathrm{hpt}$. Gli3 $\mathrm{A}^{\mathrm{HIGH}}$ is sufficient to induce Olig2 $6 \mathrm{hpt}$ but few cells up-regulate Nkx2.2 at $6 \mathrm{hpt}$. Nkx2.2 is robustly induced by Gli3 $\mathrm{A}^{\mathrm{HIGH}}$ at $12 \mathrm{hpt}$. (L) In early $\mathrm{HH}$ st 12 chick embryo (16 somites) at the cervical level, Olig2 is expressed in the ventral neural tube, including the ventral midline. Low Nkx2.2 expression is detected in a small number of cells at the ventral midline. ( $M$ ) In late HH st 12 chick embryo (18 somites) at the cervical level, Olig2 is expressed in a broader ventral domain and down-regulated at the ventral midline. Nkx2.2 is induced at the ventral midline. (N) In HH st 13 chick embryo (20 somites) at the cervical level, Nkx2.2 is expressed ventrally, excluding the ventral midline. Olig2 is expressed dorsal to Nkx2.2. (O-V) Temporal requirement for hedgehog signaling in zebrafish spinal cord. $(O, S)$ Olig2 $(O)$ and Nkx2.2 $(S)$ are expressed in the appropriate domains in the zebrafish neural tube at $24 \mathrm{hpf} .(P, T)$ Embryos incubated in cyclopamine from $14 \mathrm{hpf}$ until $24 \mathrm{hpf}$ lose the expression of both Olig2 $(P)$ and Nkx2.2 $(T)$. $(Q, U)$ Embryos incubated in cyclopamine from $16 \mathrm{hpf}$ until $24 \mathrm{hpf}$ recover the expression of Olig2 (Q) but only a few cells express Nkx2.2 $(U) .(R, V)$ Expression of both Olig2 $(R)$ and Nkx2.2 $(V)$ is unaffected in embryos incubated in cyclopamine from 18 hpf until 24 hpf.

signal would have the opposite effect. To test this, we activated Shh signaling in neural tube cells for different lengths of time using SmoM2. At $12 \mathrm{hpt}$ cells electroporated with SmoM2 expressed ectopic Nkx6, Olig2, and MNR2, markers of Region B; however, few transfected cells expressed ectopic Nkx2.2 or FoxA2, Region A markers (Fig. 7A,B; data not shown). In contrast, by 24 hpt, ectopic Nkx2.2 and FoxA2-expressing cells were evident throughout the neural tube in SmoM2 transfectants (Fig. 7C; data not shown). We considered the possibility that the ectopic expression technique employed resulted in increased expression levels of the transfected construct at later time points and this accounted for the induction of increasingly ventral cell types at later time points. However, measurement of the level, in individual electroporated cells, of GFP protein expressed from the same vector transfected under the same conditions indicated that expression did not increase between $12 \mathrm{hpt}$ and $24 \mathrm{hpt}$ (Fig. 7D, green bars). This suggests that the appearance of more ventral markers at later time points was not the result of increased SmoM2 expression at $24 \mathrm{hpt}$ compared with $12 \mathrm{hpt}$.

We next examined whether exposure to SmoM2 signaling for an increased duration resulted in the accumulation of Gli activity in transfected cells, such that at later time points, cells contain higher levels of Gli activity than at the earlier time point. Assays with GBSLuc indicated that the level of Gli activity in SmoM2 transfected embryos was similar at $12 \mathrm{hpt}$ and $24 \mathrm{hpt}$ (Fig. 7D, blue bars). These data are consistent with the stable expression levels of transfected protein over the time course of the experiment. The data therefore sug- 
gest that transfected cells integrate the level of Shh signaling over time rather than responding solely to an increased amount of signaling at later time points.

To test whether the duration of Gli activity influenced the response of neural cells, we examined embryos transfected with Gli3A ${ }^{\mathrm{MED}}$. Measurements of the level of Gli3A $^{\mathrm{MED}}$ protein in individual electroporated cells between $24 \mathrm{hpt}$ and $72 \mathrm{hpt}$ indicated that the amount of Gli3A $^{\text {MED }}$ expression peaked at $24 \mathrm{hpt}$ and subsequently decreased over the time course of the experiment (Fig. 7I). Moreover, in vivo luciferase assays with GBS-Luc, which measures both ectopic and endogenous Gli activity, indicated that in embryos electroporated with Gli3A $^{\mathrm{MED}}$ the level of Gli activity was constant between $12 \mathrm{hpt}$ and $72 \mathrm{hpt}$ (Fig. 7J; data not shown). To examine the consequence of exposure to different durations of Gli activity, we examined the expression of region $\mathrm{A}$ and region $\mathrm{B}$ markers at different time points post-transfection. Robust induction of Nkx6, Olig2, and MNR2 was evident 24-48 hpt; nevertheless, few if any transfected cells ectopically expressed Nkx2.2 or FoxA2 (Fig. 7E,F,H; data not shown). In contrast, ectopic induction of Nkx2.2 and FoxA2 was present in embryos transfected with Gli3A $\mathrm{A}^{\mathrm{MED}} 72 \mathrm{hpt}$ (Fig. 7G,H; data not shown). To rule out the possibility that neural cells were not competent to induce region A markers at early time points, we analyzed cells transfected with Gli3 $\mathrm{A}^{\mathrm{HIGH}}$. Transfection of Gli3 $\mathrm{A}^{\mathrm{HIGH}}$ was sufficient to induce both $\mathrm{Nkx} 2.2$ and Olig2 at $12 \mathrm{hpt}$ and $24 \mathrm{hpt}$ (Fig. $7 \mathrm{~K}$; data not shown). At $6 \mathrm{hpt}$ ectopic Olig2 induction was evident while expression of $\mathrm{Nkx} 2.2$ was observed in a lower proportional of cells (Fig. $7 \mathrm{~K}$; data not shown). Similar to Gli3A ${ }^{\mathrm{MED}}$, measurements of protein levels in individual electroporated cells indicated that the amounts of Gli3 $\mathrm{A}^{\mathrm{HIGH}}$ decreased over the time course of the experiment and in vivo luciferase assays with GBS-Luc indicated that Gli activity peaked at $12 \mathrm{hpt}$ (data not shown). Taken together these data suggest that in addition to the strength of Gli activity, the duration of Gli activity is a critical parameter determining the response of ventral neural tube cells.

These data suggest that the induction of Region B and Region A should proceed sequentially in vivo. We therefore examined the profile of Nkx2.2 and Olig2 induction in chick embryos. At somite level 12-14 in HH st 12 (16 som) embryos, Olig2 was detected in a domain of cells that encompassed the ventral midline (Fig. 7Li). Low levels of $\mathrm{Nkx} 2.2$ were detected in a small number of the ventral-most cells adjacent to the underlying notochord (Fig. 7Lii). In slightly older embryos HH st 12 (18 som), in regions level with somite $12-14$, robust Nkx2.2 expression was induced in cells of the ventral midline (Fig. 7Mii) and Olig2 expression was observed in a broader ventral domain but had been repressed in cells at the ventral midline (Fig. 7Mi). In HH st 13 embryos (20 som) at somite level 12-14, the more familiar pattern of Nkx2.2 and Olig2 expression began to resolve: $\mathrm{Nkx} 2.2$ was found in a ventral domain excluding the ventral midline (Fig. 7Nii), and dorsal to Nkx2.2-expressing cells, Olig2 was expressed (Fig. $7 \mathrm{Ni}$ ). This dynamic pat- tern of Nkx2.2 and Olig2 expression is consistent with the idea that individual progenitor cells are progressively ventralized and the mature expression domains are the result of the temporal integration of signaling during the early stages of neural tube patterning.

To test the idea that cells integrate Shh signaling over time, we used the Shh signaling inhibitor cyclopamine and took advantage of the zebrafish system where the concentration and timing of cyclopamine treatment can most accurately be controlled (Chen et al. 2001; Karlstrom et al. 2003; Wolff et al. 2003; Hirsinger et al. 2004; Park et al. 2004). We found that in wild-type zebrafish embryos $24 \mathrm{~h}$ post-fertilization (hpf), Nkx2.2 and Olig2 were expressed in the neural tube in the equivalent domains to that seen in mouse and chick embryos (Fig. $70, S$; data not shown). In embryos in which Shh signaling had been blocked from the time of fertilization, neither Nkx2.2 nor Olig2 were expressed (data not shown). To identify the temporal requirements for Shh signaling, we undertook a time course in which developing embryos were transferred into cyclopamine at predetermined times after fertilization. Neither Nkx2.2 nor Olig2 were expressed in the spinal cord of embryos that were placed into cyclopamine prior to $14 \mathrm{hpf}$ (Fig. 7P,T). Conversely, if embryos were transferred into cyclopamine $18 \mathrm{hpf}$ or later, expression of the two markers appeared normal (Fig. 7R,V). In contrast, if embryos were transferred into cyclopamine $16 \mathrm{hpf}$ near normal expression of Olig2 was detected in the spinal cord, but few if any cells expressed Nkx2.2 (Fig. 7Q,U). Together these data indicate that Nkx2.2 and Olig2 are differentially sensitive to Shh signaling and support the idea that the dorsal-ventral identity of a progenitor depends on a combination of the strength and duration of graded Shh signaling.

\section{Discussion}

The ability of graded Shh signaling to organize cellular pattern serves as a paradigm for vertebrate morphogen gradients. Shh signaling is sufficient to control cell fate along the dorsal-ventral axis of the neural tube and a range of evidence indicates that Shh functions at a long range to elicit distinct outputs at different concentration thresholds (Ericson et al. 1997b; Matise et al. 1998; Hynes et al. 2000; Briscoe et al. 2001; Gritli-Linde et al. 2001; Lewis et al. 2001; Wijgerde et al. 2002). Major interest resides, therefore, in understanding the mechanisms by which Shh signaling controls gene expression and cell patterning. In this study we provide evidence that an activity and temporal gradient of Gli-mediated transcription is sufficient to emulate graded Shh signaling. Our data indicate that Shh signaling increases Glidependent transcription in vivo and that Gli activity in the absence of ongoing Shh signaling is able to mediate patterning of the ventral neural tube. Moreover, the analysis indicates that the two- to threefold incremental changes in Shh concentration that generate alternative neuronal subtypes in vitro can be mimicked by similar changes in the level of Gli activity in vivo. This suggests 
that the Shh signaling pathway does not substantially amplify signal differences during transduction to the nucleus. Instead, modest differences in the amount or duration of Gli activity are able to differentially control gene expression. Together, these data suggest that graded Shh signaling is translated into a gradient of Gli activity and that small, cell-autonomous changes in the level of Gli activity is sufficient to orchestrate ventral neural tube patterning (Fig. 8).

\section{A gradient of Gli activity is sufficient to mediate graded Shh signaling}

The principal characteristic of a morphogen gradient is that cells activate and/or repress different sets of genes at different concentration thresholds. In the case of Shh signaling, a number of studies indicate that Gli-mediated transcription plays a central role in this process. Mouse embryos lacking individual Gli proteins have specific, well-defined defects in ventral neural tube patterning (Matise et al. 1998; Park et al. 2000; Bai and Joyner 2001; Bai et al. 2002; Persson et al. 2002). Furthermore, although MNs and V0, V1, and V2 neurons are generated in mouse embryos lacking all Gli protein activity, the spatial organization of these cell types is severely disrupted (Bai et al. 2004; Lei et al. 2004) and the different neuronal subtypes are generated in an apparently stochastic manner, irrespective of their position along the dorsal-ventral axis. These data raise the question of whether Gli-mediated transcription is sufficient to recapitulate Shh signaling and how Gli proteins provide po-
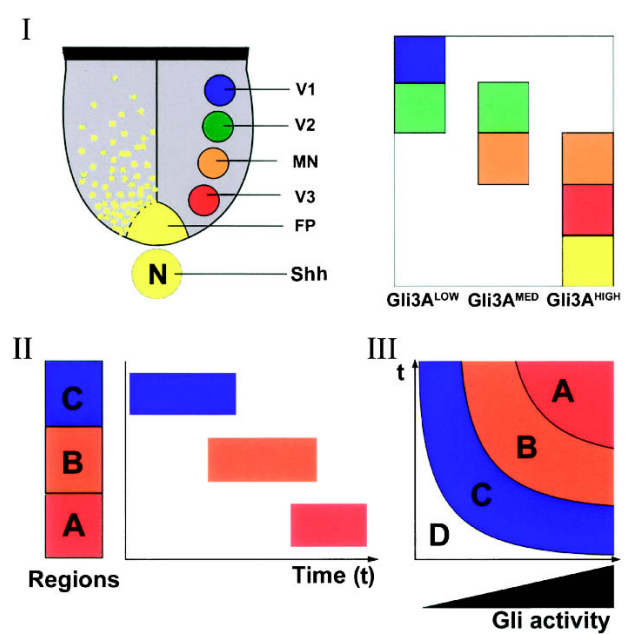

Figure 8. A model of Gli function in ventral neural tube patterning. (I) A gradient of Gli transcriptional activity emulates graded Shh signaling and is sufficient to orchestrate patterning of the ventral neural tube. (II) In addition to signal strength, signal duration determines dorsal-ventral patterning. Exposure to a fixed level of Shh signaling for an increasing time results in the incremental induction of more ventral markers. (III) Levels of Shh/Gli activity are integrated over time; thus both signal strength and signal duration contribute to the patterning of the neural tube. sitional information to the developing neural tube. Our data indicate that the full repertoire of ventral identities can be generated with different levels of Gli activity, even in the absence of ongoing Shh signaling. Moreover, the level of Gli activity necessary to generate a particular cell fate corresponds to its position of generation in vivo. These data indicate therefore, that Gli-dependent transcription is sufficient to cell-autonomously mediate Shh signaling and suggest that the graded activity of Shh is translated into a gradient of Gli activity.

If graded Gli activity is sufficient to mediate Shh signaling, how is a gradient constructed from the endogenous Gli proteins? Addressing this question is complicated by the presence of three Gli proteins with different expression profiles in the neural tube, which have been assigned unique as well as overlapping functions (Hui et al. 1994; Marigo et al. 1996; Lee et al. 1997; Sasaki et al. 1997; Ruiz i Altaba 1998; Dai et al. 1999; Aza-Blanc et al. 2000; Wang et al. 2000; Ingham and McMahon 2001; Jacob and Briscoe 2003; Ruiz i Altaba et al. 2003). Taken together with the findings presented in this study, the data suggest that the aggregate of the individual responses of each Gli protein to a given concentration of Shh results in a gradient of Gli activity in the neural tube. In this view, in the absence of Shh signaling, Gli repressor activity dominates; low levels of Shh signaling would inhibit Gli repressor formation, facilitating the production of Region C. At higher levels of Shh signaling, repressor activity would be absent and it seems likely that a combination of Gli2 and Gli3 activators direct the generation of Region B. At the highest levels of Shh signaling, Gli3 expression is repressed and the production of Gli2 activator isoforms induces Gli1 expression and the generation of Region A. This model also provides an explanation for the different neural patterning defects observed in mouse and zebrafish embryos lacking the same Gli ortholog (Karlstrom et al. 2003): Small differences in the activity and/or response of the orthologs in the two species result in different profiles of functional overlap and redundancy. Consequently, lack of an ortholog in mouse and zebrafish has different effects on the resulting gradient of Gli activity.

\section{Small changes in the level of Gli activity are sufficient to orchestrate dorsal-ventral patterning}

In vitro data indicate that incremental two- to threefold changes in Shh concentration are sufficient to direct the generation of the different cell types characteristic of the ventral neural tube (Ericson et al. 1997a). Two mechanisms can be envisioned by which these changes in the extracellular concentration of signal could be quantitatively transduced to the nucleus. First, differences could be amplified during intracellular signal transduction so that small extracellular differences result in substantial intracellular differences in transcriptional activity. Signaling pathways involving kinase cascades, such as the mitogen-activated protein (MAP) kinase pathway, have been proposed to operate in this manner (Duffy and Perrimon 1996). A second possibility is that the small 
differences in receptor activation are maintained at each step inside the cell, so that the level of transcriptional activity directly reflects the extracellular concentration of the signal (Shimizu and Gurdon 1999). Our data suggest Shh signaling adopts this latter strategy. The three dominant active Gli constructs used in this study differ in activity by increments of two- to threefold; these are sufficient to recapitulate ventral neural tube patterning and simulate the effect of exposure of neural explants to two- to threefold differences in Shh concentration (Ericson et al. 1997a). Consistent with this, we find that Gli3A $A^{\text {HIGH }}$ expresses four- to sixfold more protein than Gli3 $\mathrm{A}^{\mathrm{LOW}}$ and that these constructs generate gene expression profiles produced, in vitro, by similar differences in Shh concentration. Moreover, cells transfected with Gli3 $\mathrm{A}^{\mathrm{HIGH}}$ that express $\mathrm{Nkx} 2.2$ contain on average $\sim 50 \%$ higher levels of Gli3 $\mathrm{A}^{\mathrm{HIGH}}$ than transfectants expressing Olig2. Consistent with this, production of Nkx2.2 expressing progenitors requires concentrations of Shh in excess of $3 \mathrm{nM}$, while $\mathrm{MN}$ generation peaks at $2 \mathrm{nM}$ (Ericson et al. 1997a). Together the data support the idea that the two- to threefold differences in extracellular Shh concentration are transduced by similar small differences in the level of Gli activity and suggest that little if any amplification of the signal occurs during signal transduction. Analyses of other morphogen signaling pathways (Shimizu and Gurdon 1999; Stathopoulos and Levine 2002a) have led to similar conclusions; thus a common feature of graded signals appears to be that differences in signal strength are relayed directly, without amplification, to the nucleus.

The demonstration that small changes in the level of Gli activity are sufficient to differentially regulate transcription requires genes that are able to respond to these modest changes in activity. The mechanism by which this is achieved is not yet clear. Moreover, in none of the examples of graded signals has this been fully elucidated. Perhaps best understood is the Drosophila maternal factor, Dorsal (Stathopoulos and Levine 2002a,b; Stathopoulos et al. 2002). These studies have defined two general strategies by which graded transcriptional activity can control differential gene expression. First, the binding affinity of regulatory elements within a gene can control the concentration at which a gene is activated (Jiang and Levine 1993). A second strategy involves other regulatory regions within a gene that determine the threshold response of a gene to a graded activator or repressor: The presence of a synergistic activator lowers the threshold necessary to activate expression while an inhibitor increases the threshold level required for activation (Ip et al. 1992). It seems likely that this strategy may be of relevance for the control of Shh responsive genes in the neural tube. In mouse embryos lacking all Gli activity, although the pattern of generation is severely disrupted, many ventral neural tube fates are generated (Bai et al. 2004; Lei et al. 2004), indicating that although Gli proteins are required to provide positional identity, factors other than Gli proteins can induce the expression of ventral genes. Consistent with this, SoxB1 proteins have been proposed to act as transactivating factors in neural progenitors (Bylund et al. 2003; Graham et al. 2003); moreover, signals in addition to Shh have been proposed to be capable of regulating gene expression characteristic of the ventral neural tube (Litingtung and Chiang 2000; Diez del Corral et al. 2003; Novitch et al. 2003). Thus it seems plausible that the differential responses of progenitor homeodomain genes are controlled by a combination of Gli-binding sites and additional regulatory elements that bind positive and/or negative factors. These additional regulatory elements could determine the threshold at which a gene will respond to Shh and provide a mechanism to "prepattern" the neural tube. Moreover, the previously described cross-repressive interactions between class I and class II homeodomain proteins expressed in complementary domains (Briscoe et al. 2000) would act to ensure a congruent expression profile in progenitors so that individual progenitor cells generate appropriate, distinct neuronal subtypes. A complete molecular understanding of how this operates awaits the identification and characterization of the elements necessary to direct expression of the progenitor homeodomain genes in the neural tube.

\section{Integrating strength and duration of Shh signaling}

Our data raise the possibility that the duration as well as the strength of Shh-Gli signaling influences ventral neural tube patterning as has been recently proposed in the limb (Ahn and Joyner 2004; Harfe et al. 2004). Increased duration of active Shh signaling results in the induction of markers characteristic of more ventral regions of the neural tube, while the premature termination of signaling differentially affects the expression of markers characteristic of distinct dorsal-ventral domains of the neural tube (Fig. 7). This suggests that cells respond to Shh by integrating signal strength over time and not simply responding to the peak signal strength reached. This temporal integration does not appear to be due, solely, to the accumulation of increasing amounts of Gli activity in responding cells; for example, increasing the time of exposure of cells to Gli3A $\mathrm{A}^{\mathrm{MED}}$ results in the ectopic induction of markers normally only seen in Gli3 $\mathrm{A}^{\mathrm{HIGH}}$ transfected embryos despite the lack of increase in the level of Gli3A $\mathrm{AED}^{\mathrm{MED}}$ activity. One possible explanation, therefore, is a mechanism that has been termed the "sequential cell context" model or "self-enabling mechanism" (Pages and Kerridge 2000; Kang et al. 2003). In this model, signaling initially regulates an early set of target genes that change the cell context to facilitate the expression of a later set of genes. In the case of $\mathrm{Nkx} 2.2$ induction by Shh signaling, a candidate for an early target gene would be repression of Pax6. Gain- and loss-offunction data have provided evidence that Pax6 represses Nkx2.2 expression (Ericson et al. 1997b; Briscoe et al. 2000). Thus, early Shh signaling could down-regulate Pax6, providing the appropriate cell context, and then continued Shh signaling would induce the activation of Nkx2.2.

If increased duration of Shh signaling is sufficient to induce increasingly ventral identities, what ensures that 
the entire spinal cord is not ventralized as development and Shh signaling proceeds? An explanation for this may reside in the autoinhibitory characteristic of Shh signaling. Responses to Shh signaling include the induction of Ptc and HIP (Chuang and McMahon 1999; Pearse et al. 2001), which act as extracellular inhibitors of signaling; it is possible that cell-autonomous inhibitors of Shh signaling are also induced by Shh. The induction of inhibitors of Shh signaling acts as an auto-desensitization mechanism providing a means to limit the ventralization of cells in the neural tube. This model could also account for the high levels of Shh signaling required for the induction of the most ventral cell types. Thus, in the initial stages of Shh signaling, in which the appropriate cell context is established, partial desensitization of cells to Shh occurs by the up-regulation of genes such as Ptc. This would have the consequence that higher levels of Shh signaling are required for the induction of the later, second set of genes. This model also predicts that cells that have the appropriate cell context prior to receiving Shh signaling would be able to induce target genes at lower thresholds of signal than normally observed. This could explain the increased sensitivity to Shh signaling of, for example, cells lacking Pax6 expression (Ruiz i Altaba et al. 1995). This type of model may provide a means for other signals to influence ventral patterning and suggests that these signals may be integrated at the level of the control of individual genes.

\section{Materials and methods}

\section{Constructs}

Gli3 activator constructs (Gli3A) were designed using human Gli3 (hGli3) (accession no. XP_004833) and cloned into the pCAGGS (Niwa et al. 1991) expression vector engineered to bicistronically express nuclear targeted GFP (IRES NLS-GFP pCAGGS). Gli3 ${ }^{\Delta \mathrm{N} 1}$ encodes amino acids $289-1580$ of hGli3. $\mathrm{Gli}^{\Delta \mathrm{N} 2}$ encodes amino acids $468-1580$ of hGli3. Both Gli3 ${ }^{\Delta \mathrm{N} 1}$ and Gli $3^{\Delta \mathrm{N} 2}$ are tagged at their $\mathrm{N}$ terminus with five repeats of the myc epitope (MEQKLISEEDLNE). GFP was removed from the Gli3 ${ }^{\Delta \mathrm{N} 1}$ and Gli3 ${ }^{\Delta \mathrm{N} 2}$ IRES NLS-GFP pCAGGS in order to use the constructs for protein quantitation assays and to cotransfect with the Gli-binding site's GFP (GBS-GFP) reporter plasmid (see below). Gli3 ${ }^{\Delta \mathrm{N} 2}$ was also cloned in the mammalian expression vector pECE (Ellis et al. 1986). For the in vivo luciferase assay the Firefly-luciferase reporter gene carrying eight copies of the Gli-binding site from the FoxA2/HNF3 $\beta$ floor plate enhancer (GBS-Luc) was used (Sasaki et al. 1997). A Gli-binding site reporter construct with NLS-GFP as reporter gene (GBSGFP) was prepared by replacing the Firefly-luciferase coding sequence of GBS-Luc with NLS-GFP coding sequence. All subcloning techniques were performed according to Sambrook et al. (1989).

\section{Chick in ovo electroporation}

All constructs were electroporated into the neural tube of $\mathrm{HH}$ st 10-12 (Hamburger and Hamilton 1951) chick embryos (Briscoe et al. 2000). After 6-72 h, embryos were fixed and processed for immunohistochemistry or homogenized in order to produce ex- tracts for the in vivo luciferase assay as described previously (Briscoe et al. 2000).

\section{Immunohistochemistry and in situ} hybridization histochemistry

Immunohistochemical localization of proteins was performed as described (Yamada et al. 1993; Briscoe et al. 2000). Antibodies used have been described previously (Liem et al. 1995; Nakagawa and Takeichi 1995; Ericson et al. 1996, 1997b; Tanabe et al. 1998; Arber et al. 1999; Pierani et al. 1999; Vallstedt et al. 2001; Muller et al. 2002; Cheung and Briscoe 2003). Monoclonal $\beta \mathrm{Gal}$ antibody was purchased from Sigma (G8021). Sheep GFP antibody was purchased from Biogenesis (4745-1051). Images were collected on Leica TCS SP2 confocal microscope. In situ hybridization was performed as described (Schaeren-Wiemers and Gerfin-Moser 1993), using probes for Dbx2 (Pierani et al. 1999), Ptc1 and Ptc2 (Pearse et al. 2001), and Gli1 (Marigo et al. 1996). In situ hybridization on zebrafish embryos was performed as described (Thisse et al. 1993) using probes for Olig2 (Park et al. 2002) and Nkx2.2 (Barth and Wilson 1995).

\section{Quantification of protein levels}

Immunohistochemistry was performed using matched embryo samples as described above using $7-\mu \mathrm{m}$-thick cryosections. Rabbit anti-myc antibody (Arber et al. 1999) or rabbit anti-GFP antibody (IgG fragment, Molecular Probes) and goat anti-rabbit Alexa Fluor 594 (Molecular Probes) were used to detect the myctagged $\mathrm{Gli} 3^{\Delta \mathrm{N} 1}$ and $\mathrm{Gli} 3^{\Delta \mathrm{N} 2}$ proteins or GFP protein, respectively. Images were collected on an Olympus IX70 inverted microscope with a Prinston Instruments MICROMAX (5 MHz) air-cooled interline CCD camera using Softworx image acquisition software (Applied Precision). Intensity of fluorescence was measured in the nuclei of the cells, indicated by DAPI staining, using NIH software Image J. Average intensity of fluorescence per pixel was calculated after normalization for exposure times.

\section{Luciferase assay}

SmoM2, Gli3A constructs, or pCAGGS as control were electroporated in chick embryos along with (GBS-Luc) a firefly luciferase reporter construct containing eight repeats of the Gli binding sequence (Sasaki et al. 1999) and a Renilla-luciferase reporter carrying the CMV immediate early enhancer promoter (Promega) for normalization. Embryos were homogenized with a douncer in Passive Lysis Buffer on ice and measurement of Firefly and Renilla luciferase activities was performed using the Dual Luciferase Reporter Assay System (Promega).

\section{Cyclopamine treatment}

Beginning at 14, 16, and 18 hpf, wild-type zebrafish embryos were treated with $10 \mu \mathrm{M}$ cyclopamine (Toronto Research Chemicals) dissolved in Danieau solution (Nasevicius and Ekker 2000) and $0.1 \%$ ethanol. Controls consisted of corresponding incubations in Danieau solution alone or $0.1 \%$ ethanol in Danieau solution. There were no differences in the neural expression of Nkx2.2 and Olig2 between wild-type embryos and embryos incubated in $0.1 \%$ ethanol.

\section{Acknowledgments}

We thank H. Sasaki for the GBS-Luc reporter construct, A. Rosenthal for SmoM2, A.P. McMahon for mouse HIP cDNA, 
W.D. Richardson for zebrafish Olig2 cDNA, S. Wilson for zebrafish Nkx2.2 cDNA, and M. Logan for chick Ptc1, Ptc2, and Gli1 cDNAs. We also thank S. Morton and T.M. Jessell for antibodies and $\mathrm{H}$. Edlund for pan Nkx6 antisera. The monoclonal antibodies against Msx1 (4G1, developed by K.F. Liem) and Cadherin7 (CCD7-1, developed by S. Nakagawa) were obtained from the Developmental Studies Hybridoma Bank developed under the auspices of the NICHD and maintained by The University of Iowa, Department of Biological Services, Iowa City, IA. We are grateful to J. Ericson, A. Gould, T.M. Jessell, and J-P. Vincent for helpful discussions and comments on the manuscript. This work was supported by the MRC and by EC network grants, Brainstem Genetics (QLG2-CT-2001-01467), and Stembridge (QLG3-CT-2002-01141). F.U. is supported by an EMBO Long Term Fellowship.

\section{References}

Ahn, S. and Joyner, A.L. 2004. Dynamic changes in the response of cells to positive hedgehog signaling during mouse limb patterning. Cell 118: 505-516.

Arber, S., Han, B., Mendelsohn, M., Smith, M., Jessell, T.M., and Sockanathan, S. 1999. Requirement for the homeobox gene $\mathrm{Hb} 9$ in the consolidation of motor neuron identity. Neuron 23: 659-674.

Aza-Blanc, P., Lin, H.Y., Ruiz i Altaba, A., and Kornberg, T.B. 2000. Expression of the vertebrate Gli proteins in Drosophila reveals a distribution of activator and repressor activities. Development 127: 4293-4301.

Bai, C.B. and Joyner, A.L. 2001. Glil can rescue the in vivo function of Gli2. Development 128: 5161-5172.

Bai, C.B., Auerbach, W., Lee, J.S., Stephen, D., and Joyner, A.L. 2002. Gli2, but not Gli1, is required for initial Shh signaling and ectopic activation of the Shh pathway. Development 129: 4753-4761.

Bai, C.B., Stephen, D., and Joyner, A.L. 2004. All mouse ventral spinal cord patterning by hedgehog is Gli dependent and involves an activator function of Gli3. Dev. Cell 6: 103-115.

Barth, K.A. and Wilson, S.W. 1995. Expression of zebrafish $\mathrm{nk} 2.2$ is influenced by sonic hedgehog/vertebrate hedgehog-1 and demarcates a zone of neuronal differentiation in the embryonic forebrain. Development 121: 1755-1768.

Briscoe, J. and Ericson, J. 2001. Specification of neuronal fates in the ventral neural tube. Curr. Opin. Neurobiol. 11: 43-49.

Briscoe, J., Sussel, L., Serup, P., Hartigan-O'Connor, D., Jessell, T.M., Rubenstein, J.L., and Ericson, J. 1999. Homeobox gene Nkx2.2 and specification of neuronal identity by graded Sonic hedgehog signalling. Nature 398: 622-627.

Briscoe, J., Pierani, A., Jessell, T.M., and Ericson, J. 2000. A homeodomain protein code specifies progenitor cell identity and neuronal fate in the ventral neural tube. Cell 101: 435445.

Briscoe, J., Chen, Y., Jessell, T.M., and Struhl, G. 2001. A hedgehog-insensitive form of patched provides evidence for direct long-range morphogen activity of sonic hedgehog in the neural tube. Mol. Cell 7: 1279-1291.

Bylund, M., Andersson, E., Novitch, B.G., and Muhr, J. 2003. Vertebrate neurogenesis is counteracted by Sox1-3 activity. Nat. Neurosci. 6: 1162-1168.

Chen, W., Burgess, S., and Hopkins, N. 2001. Analysis of the zebrafish smoothened mutant reveals conserved and divergent functions of hedgehog activity. Development 128: 2385-2396.

Cheung, M. and Briscoe, J. 2003. Neural crest development is regulated by the transcription factor Sox9. Development 130: $5681-5693$.
Chuang, P.T. and McMahon, A.P. 1999. Vertebrate Hedgehog signalling modulated by induction of a Hedgehog-binding protein. Nature 397: 617-621.

Dai, P., Akimaru, H., Tanaka, Y., Maekawa, T., Nakafuku, M., and Ishii, S. 1999. Sonic Hedgehog-induced activation of the Gli1 promoter is mediated by GLI3. J. Biol. Chem. 274: 8143-8152.

Diez del Corral, R., Olivera-Martinez, I., Goriely, A., Gale, E., Maden, M., and Storey, K. 2003. Opposing FGF and retinoid pathways control ventral neural pattern, neuronal differentiation, and segmentation during body axis extension. Neuron 40: 65-79.

Ding, Q., Motoyama, J., Gasca, S., Mo, R., Sasaki, H., Rossant, J., and Hui, C.C. 1998. Diminished Sonic hedgehog signaling and lack of floor plate differentiation in Gli2 mutant mice. Development 125: 2533-2543.

Duffy, J.B. and Perrimon, N. 1996. Recent advances in understanding signal transduction pathways in worms and flies. Curr. Opin. Cell Biol. 8: 231-238.

Ellis, L., Clauser, E., Morgan, D.O., Edery, M., Roth, R.A., and Rutter, W.J. 1986. Replacement of insulin receptor tyrosine residues 1162 and 1163 compromises insulin-stimulated kinase activity and uptake of 2-deoxyglucose. Cell 45: 721732.

Ericson, J., Morton, S., Kawakami, A., Roelink, H., and Jessell, T.M. 1996. Two critical periods of Sonic Hedgehog signaling required for the specification of motor neuron identity. Cell 87: 661-673.

Ericson, J., Briscoe, J., Rashbass, P., van Heyningen, V., and Jessell, T.M. 1997a. Graded sonic hedgehog signaling and the specification of cell fate in the ventral neural tube. Cold Spring Harb. Symp. Quant. Biol. 62: 451-466.

Ericson, J., Rashbass, P., Schedl, A., Brenner-Morton, S., Kawakami, A., van Heyningen, V., Jessell, T.M., and Briscoe, J. 1997b. Pax6 controls progenitor cell identity and neuronal fate in response to graded Shh signaling. Cell 90: 169-180.

Graham, V., Khudyakov, J., Ellis, P., and Pevny, L. 2003. SOX2 functions to maintain neural progenitor identity. Neuron 39: 749-765.

Gritli-Linde, A., Lewis, P., McMahon, A.P., and Linde, A. 2001. The whereabouts of a morphogen: Direct evidence for shortand graded long-range activity of hedgehog signaling peptides. Dev. Biol. 236: 364-386.

Gurdon, J.B. and Bourillot, P.Y. 2001. Morphogen gradient interpretation. Nature 413: 797-803.

Hamburger, V. and Hamilton, H.L. 1951. A series of normal stages in the development of the chick embryo. J. Morphol. 88: 49-92.

Harfe, B.D., Scherz, P.J., Nissim, S., Tian, H., McMahon, A.P., and Tabin, C.J. 2004. Evidence for an expansion-based temporal Shh gradient in specifying vertebrate digit identities. Cell 118: 517-528.

Hirsinger, E., Stellabotte, F., Devoto, S.H., and Westerfield, M. 2004. Hedgehog signaling is required for commitment but not initial induction of slow muscle precursors. Dev. Biol. 275: $143-157$.

Hui, C.C., Slusarski, D., Platt, K.A., Holmgren, R., and Joyner, A.L. 1994. Expression of three mouse homologs of the Drosophila segment polarity gene cubitus interruptus, Gli, Gli2, and Gli-3, in ectoderm- and mesoderm-derived tissues suggests multiple roles during postimplantation development. Dev. Biol. 162: 402-413.

Hynes, M., Ye, W., Wang, K., Stone, D., Murone, M., Sauvage, F., and Rosenthal, A. 2000. The seven-transmembrane receptor smoothened cell-autonomously induces multiple ventral cell types. Nat. Neurosci. 3: 41-46. 
Ingham, P.W. and McMahon, A.P. 2001. Hedgehog signaling in animal development: Paradigms and principles. Genes \& Dev. 15: 3059-3087.

Ip, Y.T., Park, R.E., Kosman, D., Yazdanbakhsh, K., and Levine, M. 1992. dorsal-twist interactions establish snail expression in the presumptive mesoderm of the Drosophila embryo. Genes \& Dev. 6: 1518-1530.

Jacob, J. and Briscoe, J. 2003. Gli proteins and the control of spinal-cord patterning. EMBO Rep. 4: 761-765.

Jessell, T.M. 2000. Neuronal specification in the spinal cord: Inductive signals and transcriptional codes. Nat. Rev. Genet. 1: 20-29.

Jiang, J. and Levine, M. 1993. Binding affinities and cooperative interactions with bHLH activators delimit threshold responses to the dorsal gradient morphogen. Cell 72: 741-752.

Kang, Y., Chen, C.R., and Massague, J. 2003. A self-enabling TGF $\beta$ response coupled to stress signaling: Smad engages stress response factor ATF3 for Id1 repression in epithelial cells. Mol. Cell 11: 915-926.

Karlstrom, R.O., Tyurina, O.V., Kawakami, A., Nishioka, N., Talbot, W.S., Sasaki, H., and Schier, A.F. 2003. Genetic analysis of zebrafish gli1 and gli2 reveals divergent requirements for gli genes in vertebrate development. Development 130: 1549-1564.

Lawrence, P.A. and Struhl, G. 1996. Morphogens, compartments, and pattern: Lessons from Drosophila? Cell 85: 951961.

Lee, J., Platt, K.A., Censullo, P., and Ruiz i Altaba, A. 1997. Gli1 is a target of Sonic hedgehog that induces ventral neural tube development. Development 124: 2537-2552.

Lei, Q., Zelman, A.K., Kuang, E., Li, S., and Matise, M.P. 2004. Transduction of graded Hedgehog signaling by a combination of Gli2 and Gli3 activator functions in the developing spinal cord. Development 131: 3593-3604.

Lewis, P.M., Dunn, M.P., McMahon, J.A., Logan, M., Martin, J.F., St-Jacques, B., and McMahon, A.P. 2001. Cholesterol modification of sonic hedgehog is required for long-range signaling activity and effective modulation of signaling by Ptc1. Cell 105: 599-612.

Liem Jr., K.F., Tremml, G., Roelink, H., and Jessell, T.M. 1995. Dorsal differentiation of neural plate cells induced by BMPmediated signals from epidermal ectoderm. Cell 82: 969-979.

Litingtung, Y. and Chiang, C. 2000. Specification of ventral neuron types is mediated by an antagonistic interaction between Shh and Gli3. Nat. Neurosci. 3: 979-985.

Marigo, V., Johnson, R.L., Vortkamp, A., and Tabin, C.J. 1996. Sonic hedgehog differentially regulates expression of GLI and GLI3 during limb development. Dev. Biol. 180: 273-283.

Matise, M.P., Epstein, D.J., Park, H.L., Platt, K.A., and Joyner, A.L. 1998. Gli2 is required for induction of floor plate and adjacent cells, but not most ventral neurons in the mouse central nervous system. Development 125: 2759-2770.

Muhr, J., Andersson, E., Persson, M., Jessell, T.M., and Ericson, J. 2001. Groucho-mediated transcriptional repression establishes progenitor cell pattern and neuronal fate in the ventral neural tube. Cell 104: 861-873.

Muller, T., Brohmann, H., Pierani, A., Heppenstall, P.A., Lewin, G.R., Jessell, T.M., and Birchmeier, C. 2002. The homeodomain factor lbxl distinguishes two major programs of neuronal differentiation in the dorsal spinal cord. Neuron 34: 551-562.

Nakagawa, S. and Takeichi, M. 1995. Neural crest cell-cell adhesion controlled by sequential and subpopulation-specific expression of novel cadherins. Development 121:1321-1332.

Nasevicius, A. and Ekker, S.C. 2000. Effective targeted gene 'knockdown' in zebrafish. Nat. Genet. 26: 216-220.
Niwa, H., Yamamura, K., and Miyazaki, J. 1991. Efficient selection for high-expression transfectants with a novel eukaryotic vector. Gene 108: 193-199.

Novitch, B.G., Chen, A.I., and Jessell, T.M. 2001. Coordinate regulation of motor neuron subtype identity and pan-neuronal properties by the bHLH repressor Olig2. Neuron 31: 773789.

Novitch, B.G., Wichterle, H., Jessell, T.M., and Sockanathan, S. 2003. A requirement for retinoic acid-mediated transcriptional activation in ventral neural patterning and motor neuron specification. Neuron 40: 81-95.

Pabst, O., Herbrand, H., Takuma, N., and Arnold, H.H. 2000. NKX2 gene expression in neuroectoderm but not in mesendodermally derived structures depends on sonic hedgehog in mouse embryos. Dev. Genes Evol. 210: 47-50.

Pages, F. and Kerridge, S. 2000. Morphogen gradients. A question of time or concentration? Trends Genet. 16: 40-44.

Park, H.L., Bai, C., Platt, K.A., Matise, M.P., Beeghly, A., Hui, C.C., Nakashima, M., and Joyner, A.L. 2000. Mouse Gli1 mutants are viable but have defects in SHH signaling in combination with a Gli2 mutation. Development 127: 1593-1605.

Park, H.C., Mehta, A., Richardson, J.S., and Appel, B. 2002. olig2 is required for zebrafish primary motor neuron and oligodendrocyte development. Dev. Biol. 248: 356-368.

Park, H.C., Shin, J., and Appel, B. 2004. Spatial and temporal regulation of ventral spinal cord precursor specification by Hedgehog signaling. Development 131: 5959-5969.

Pearse II, R.V., Vogan, K.J., and Tabin, C.J. 2001. Ptc1 and Ptc2 transcripts provide distinct readouts of Hedgehog signaling activity during chick embryogenesis. Dev. Biol. 239: 15-29.

Persson, M., Stamataki, D., te Welscher, P., Andersson, E., Bose, J., Ruther, U., Ericson, J., and Briscoe, J. 2002. Dorsal-ventral patterning of the spinal cord requires Gli3 transcriptional repressor activity. Genes \& Dev. 16: 2865-2878.

Pierani, A., Brenner-Morton, S., Chiang, C., and Jessell, T.M. 1999. A sonic hedgehog-independent, retinoid-activated pathway of neurogenesis in the ventral spinal cord. Cell 97: 903-915.

Pierani, A., Moran-Rivard, L., Sunshine, M.J., Littman, D.R., Goulding, M., and Jessell, T.M. 2001. Control of interneuron fate in the developing spinal cord by the progenitor homeodomain protein Dbx1. Neuron 29: 367-384.

Qiu, M., Shimamura, K., Sussel, L., Chen, S., and Rubenstein, J.L. 1998. Control of anteroposterior and dorsoventral domains of Nkx-6.1 gene expression relative to other $\mathrm{Nkx}$ genes during vertebrate CNS development. Mech. Dev. 72: 77-88.

Ruiz i Altaba, A. 1998. Combinatorial Gli gene function in floor plate and neuronal inductions by Sonic hedgehog. Development 125: 2203-2212.

Ruiz i Altaba, A., Jessell, T.M., and Roelink, H. 1995. Restrictions to floor plate induction by hedgehog and winged-helix genes in the neural tube of frog embryos. Mol. Cell. Neurosci. 6: 106-121.

Ruiz i Altaba, A., Nguyen, V., and Palma, V. 2003. The emergent design of the neural tube: Prepattern, SHH morphogen and GLI code. Curr. Opin. Genet. Dev. 13: 513-521.

Sambrook, J., Fritsch, E.F., and Maniatis, T. 1989. Molecular cloning: A laboratory manual, 2d ed. Cold Spring Harbor Laboratory Press, Cold Spring Harbor, NY.

Sasaki, H., Hui, C., Nakafuku, M., and Kondoh, H. 1997. A binding site for Gli proteins is essential for HNF-3 $\beta$ floor plate enhancer activity in transgenics and can respond to Shh in vitro. Development 124: 1313-1322.

Sasaki, H., Nishizaki, Y., Hui, C., Nakafuku, M., and Kondoh, 
H. 1999. Regulation of Gli2 and Gli3 activities by an aminoterminal repression domain: Implication of Gli2 and Gli3 as primary mediators of Shh signaling. Development 126: 3915-3924.

Schaeren-Wiemers, N. and Gerfin-Moser, A. 1993. A single protocol to detect transcripts of various types and expression levels in neural tissue and cultured cells: In situ hybridization using digoxigenin-labelled cRNA probes. Histochemistry 100: 431-440.

Shimizu, K. and Gurdon, J.B. 1999. A quantitative analysis of signal transduction from activin receptor to nucleus and its relevance to morphogen gradient interpretation. Proc. Natl. Acad. Sci. 96: 6791-6796.

Stathopoulos, A. and Levine, M. 2002a. Dorsal gradient networks in the Drosophila embryo. Dev. Biol. 246: 57-67.

. 2002b. Linear signaling in the Toll-Dorsal pathway of Drosophila: Activated Pelle kinase specifies all threshold outputs of gene expression while the bHLH protein Twist specifies a subset. Development 129: 3411-3419.

Stathopoulos, A., Van Drenth, M., Erives, A., Markstein, M., and Levine, M. 2002. Whole-genome analysis of dorsal-ventral patterning in the Drosophila embryo. Cell 111: 687-701.

Tanabe, Y., William, C., and Jessell, T.M. 1998. Specification of motor neuron identity by the MNR2 homeodomain protein. Cell 95: 67-80.

Thisse, C., Thisse, B., Schilling, T.F., and Postlethwait, J.H. 1993. Structure of the zebrafish snaill gene and its expression in wild-type, spadetail and no tail mutant embryos. Development 119: 1203-1215.

Vallstedt, A., Muhr, J., Pattyn, A., Pierani, A., Mendelsohn, M., Sander, M., Jessell, T.M., and Ericson, J. 2001. Different levels of repressor activity assign redundant and specific roles to Nkx6 genes in motor neuron and interneuron specification. Neuron 31: 743-755.

Wang, B., Fallon, J.F., and Beachy, P.A. 2000. Hedgehog-regulated processing of Gli3 produces an anterior/posterior repressor gradient in the developing vertebrate limb. Cell 100: $423-434$.

Wijgerde, M., McMahon, J.A., Rule, M., and McMahon, A.P. 2002. A direct requirement for Hedgehog signaling for normal specification of all ventral progenitor domains in the presumptive mammalian spinal cord. Genes \& Dev. 16: 2849-2864.

Wolff, C., Roy, S., and Ingham, P.W. 2003. Multiple muscle cell identities induced by distinct levels and timing of hedgehog activity in the zebrafish embryo. Curr. Biol. 13: 1169-1181.

Wolpert, L. 1996. One hundred years of positional information. Trends Genet. 12: 359-364.

Yamada, T., Pfaff, S.L., Edlund, T., and Jessell, T.M. 1993. Control of cell pattern in the neural tube: Motor neuron induction by diffusible factors from notochord and floor plate. Cell 73: 673-686. 


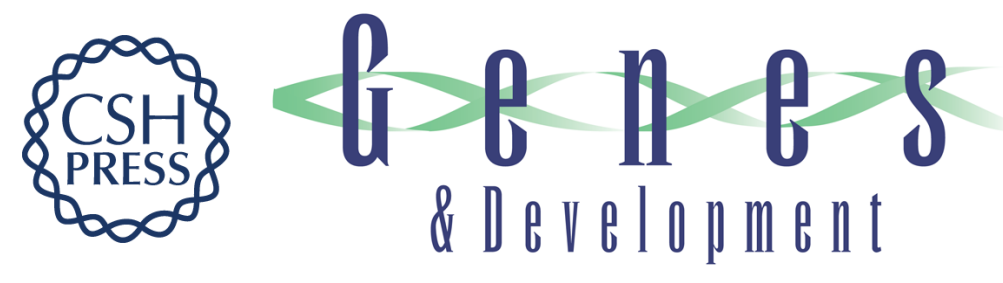

\section{A gradient of Gli activity mediates graded Sonic Hedgehog signaling in the neural tube}

Despina Stamataki, Fausto Ulloa, Stavroula V. Tsoni, et al.

Genes Dev. 2005, 19:

Access the most recent version at doi:10.1101/gad.325905

References This article cites 77 articles, 23 of which can be accessed free at: http://genesdev.cshlp.org/content/19/5/626.full.htmI\#ref-list-1

License

Email Alerting

Receive free email alerts when new articles cite this article - sign up in the box at the top Service right corner of the article or click here.

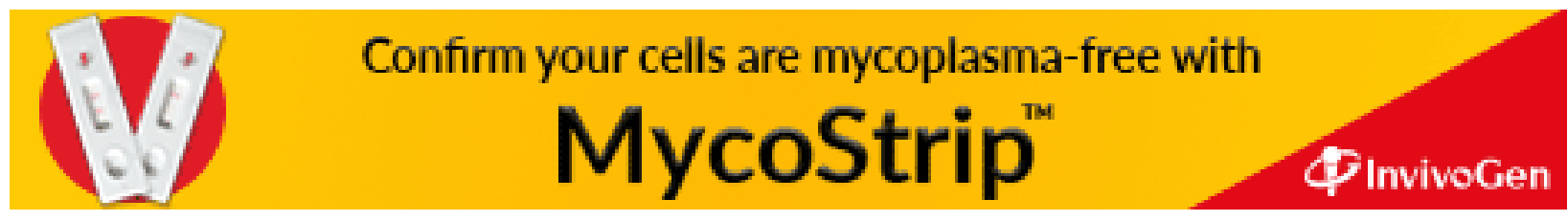

